\title{
Multibeam bathymetry and sidescan imaging of the Rivera Transform- Moctezuma Spreading Segment junction, northern East Pacific Rise: New constraints on Rivera-Pacific relative plate motion
}

\author{
William L. Bandy ${ }^{\mathrm{a},{ }^{*}}$, François Michaud ${ }^{b}$, Jérôme Dyment ${ }^{\mathrm{c}}$, Carlos A. Mortera-Gutiérrez ${ }^{\mathrm{a}}$, \\ Jacques Bourgois ${ }^{b}$, Thierry Calmus ${ }^{d}$, Marc Sosson ${ }^{e}$, Jose Ortega-Ramirez ${ }^{f}$, Jean-Yves \\ Royer $^{\mathrm{g}}$, Bernard Pontoise ${ }^{\mathrm{h}}$ and Bertrand Sichler ${ }^{\mathrm{i}}$
}

\author{
a Instituto de Geofisica, Universidad Nacional Autonoma de México, México D.F., México \\ ${ }^{\mathrm{b}}$ Géosciences Azur, (IRD-UPMC-CNRS), Villefranche sur Mer, France, and Escuela Politecnica Nacional (EPN), \\ Quito, Ecuador \\ ${ }^{c}$ CNRS, Institut de Physique du Globe de Paris, Paris, France \\ d Instituto de Geología, Universidad Nacional Autónoma de México, Hermosillo, Mexíco \\ e Géosciences Azur, Université de Nice-Sophia Antipolis, France \\ ${ }^{f}$ Geophysics Laboratory, Instituto Nacional de Antropología e Historia, Mexico \\ ${ }^{g}$ CNRS Domaines Océaniques, Brest, France \\ ${ }^{\mathrm{h}}$ Géosciences Azur, (UNAS-UPMC-CNRS-IRD), Villefrance sur Mer, France \\ 'IFREMER, Brest, France
}

*: Corresponding author : Bandy W., email address : bandy@geofisica.unam.mx

\begin{abstract}
:
To better understand the recent motion of the Pacific plate relative to the Rivera plate and to better define the limitations of the existing Rivera-Pacific plate motion models for accurately predicting this motion, total-field magnetic data, multibeam bathymetric data and sidescan sonar images were collected during the BART and FAMEX campaigns of the N/O L'Atalante conducted in April and May 2002 in the area surrounding the Moctezuma Spreading Segment of the East Pacific Rise, located offshore of Manzanillo, Mexico, at $106^{\circ} 16^{\prime} \mathrm{W}$, between $17.8^{\circ} \mathrm{N}$ and $18.5^{\circ} \mathrm{N}$. Among the main results are: (1) the principle transform displacement zone of the Rivera Transform is narrow and well defined east of $107015 \mathrm{~W}$ and these azimuths should be used preferentially when deriving new plate motion models, and (2) spreading rates along the Moctezuma Spreading Segment should not be used in plate motion studies as either seafloor spreading has been accommodated at more than one location since the initiation of seafloor spreading in the area of the Moctezuma Spreading Segment, or this spreading center is not a Rivera-Pacific plate boundary as has been previously assumed. Comparison of observed transform azimuths with those predicted by the best-fit poles of six previous models of Rivera-Pacific relative motion indicate that, in the study area, a significant systematic bias is present in the predictions of Rivera-Pacific motion. Although the exact source of this bias remains unclear, this bias indicates the need to derive a new Rivera-Pacific relative plate motion model.
\end{abstract}

Keywords: East Pacific Rise; Rivera Transform; Rivera Plate; Mexico; Plate boundary morphology; Plate motions 


\section{Introduction}

The Moctezuma Spreading Segment (MSS, Figure 1) is commonly thought (e.g. Bandy, 1992; Lonsdale, 1995) to be a recently formed, divergent boundary between the Rivera and Pacific plates and, thus, its morphology and spreading history should provide valuable constraints on the recent relative motions of the Pacific and Rivera plates. Further, since the motion of the Rivera plate relative to the North American plate can, at present, only be determined indirectly via closure about plate motion circuits that include the Rivera-Pacific plate pair, determining a well-constrained Rivera-Pacific Euler pole is critical to our understanding of the tectonic forces acting on western Mexico. Currently, several viable models (Figure 1, Table 1) exist for present-day Rivera-Pacific relative motion (i.e., DeMets and Stein, 1990; Bandy, 1992; Lonsdale, 1995; DeMets and Wilson, 1997; Bandy et al., 1998a; DeMets and Traylen, 2000; Bandy et al., 2007); hence, also for present-day Rivera-North American relative motion. The differences in the RiveraNorth American relative motions predicted by these various models are large (e.g., Kostoglodov and Bandy, 1995). In a recent study (Bandy et al., 2005) these differences prevented the investigators from stating conclusively that strain partitioning is occurring along the southern Jalisco Subduction Zone; a part of the Rivera-North American plate boundary where several large/great earthquakes have occurred in the past century (Singh et al., 1985, 2003; Zobin, 1997; Pacheco et al., 1997).

The inability to reach a consensus on the Rivera-Pacific Euler pole (Michaud et al., 1996; Bandy et al., 1998b; Wilson and DeMets, 1998) is due mainly to uncertainties arising from an incomplete coverage of high-resolution bathymetric data along the 
Rivera-Pacific boundaries (i.e. the Rivera Transform, Rivera Rise and the MSS). These uncertainties include: (1) What is the correct orientation of the Rivera Transform adjacent to the MSS? (2) Where is the point of intersection of the MSS and Rivera Transform? (3) Has the MSS been a boundary between the rigid parts of the Rivera and Pacific plates since 0.78 Ma? (4) Has there been a recent change in Rivera-Pacific relative motion? and (5) What is the correct orientation of the Rivera Transform at its junction with the Rivera Rise? To answer some of these questions and to better determine the limitations of the existing models for present-day RiveraPacific relative plate motion, multibeam bathymetric, sidescan and magnetic data were collected in the area of the junction of the Rivera Transform and the MSS during projects BART (BAthymetry of the Rivera Transform) and FAMEX conducted aboard the N/O L'Atalante during April/May 2002.

\section{Previous Work}

\subsection{Moctezuma Spreading Segment/Eastern Rivera Transform}

The MSS, first identified by Bourgois et al. (1988), is part of the East Pacific Rise (EPR) and is located at the eastern end of the Rivera Transform (Figure 1). The MSS extends $~ 65 \mathrm{~km}$ southward from the Rivera Transform (Bandy, 1992; Michaud et al., 1996; Baker et al., 2001). The gross morphology of the MSS indicates that it is the active, southward propagating rift of a paired overlapping, propagating rift system (Figure 2). Although there is some debate, the MSS is generally accepted to be a divergent boundary between the Rivera and Pacific plates (Bandy, 1992; Lonsdale, 1995; Michaud et al., 1997; DeMets and Wilson, 1997). 
Previously, high-resolution multibeam bathymetric data coverage was sparse in the majority of the area of the MSS propagator system, consisting for the most part of a single narrow swath centered on, and oriented parallel to, the axis of the MSS (Baker et al., 2001).

The age of the initiation of seafloor spreading along the MSS is uncertain. Bourgois et al. (1988) proposed, based on the width of the zone of newly created seafloor at the MSS, that spreading initiated at about 0.78 Ma. In contrast, DeMets and Wilson (1997) proposed from models of the magnetic anomaly observed at the MSS that spreading was initiated at about 1 Ma (Anomaly J or Chron 1r.1n in the terminology of Cande and Kent, 1995). Bandy and Hilde (2000) favored an initiation sometime between 0.78 and 0.9 Ma. Their rational being: (1) anomalies $1 \mathrm{R}$ and J are clearly observed along the east flank of the failed rift to the east (Figure 2) and (2) the distance between anomalies $\mathrm{J}$ and $1 \mathrm{R}$ is the same along the failed rift to the east as it is along the still active spreading segment immediately south of the failed rift. Thus spreading most likely was not initiated prior to about the later half of the time period corresponding to Anomaly 1R (between 0.78 and $0.9 \mathrm{Ma}$ ).

The location of the junction of the MSS and the Rivera Transform is also uncertain. The junction was first proposed to lie at $18^{\circ} 30^{\prime} \mathrm{N}, 106^{\circ} 15^{\prime} \mathrm{W}$ (Bourgois et al., 1988); however, Wilson and DeMets (1998) propose a location slightly to the south at the point where the axis of the MSS begins to bend sharply westward (i.e. near $18^{\circ} 29.6^{\prime} \mathrm{N}, 106^{\circ} 16^{\prime} \mathrm{W}$ ).

The orientation and the precise location of the Rivera Transform just west of the MSS is also currently the subject of debate. Bourgois et al. (1988), Bandy (1992) and Michaud et al. (1996) propose that the transform, as it approaches the MSS, runs up the side 
of the prominent escarpment that forms the northern transform wall at an azimuth of $95^{\circ}$; perpendicular to the trend of the MSS. In contrast, DeMets and Stein (1990) and DeMets and Wilson (1997) propose that the transform runs along the base of the escarpment at an azimuth of $100^{\circ}$. The plate motion model of Lonsdale (1995) predicts an azimuth of $103^{\circ}$ for the transform at its intersection with the MSS.

\subsection{Rivera-Pacific Euler Vectors}

Six viable models of the Rivera-Pacific relative motion have been derived (Table 1 and Figure 1) using the data available prior to the BART/FAMEX campaigns. Various methods, data sets and assumptions have been employed to derive these models, which has led to some confusion. Briefly, the models differ in four main areas. (1) Three models (Bandy, 1992; Lonsdale, 1995; Bandy et al., 1998a), seek to determine directly the present-day Euler pole, whereas, the other three methods derive a 0.78 Ma stage pole and assume that this is equivalent to the present day pole. (2) When used, the azimuth of the eastern end of the Rivera Transform varies between the models. (3) Some models use data along the MSS, while others do not. (4) Some models assume orthogonal spreading along the Rivera-Rise, while others do not. Clearly, one needs to reconcile these differences in the plate motion database to derive a more robust and accurate model for the recent motion of the Pacific plate relative to the Rivera plate.

Two additional models of Rivera-Pacific relative motion have been presented (Bandy et al., 2007). These models have incorporated the data collected during the BART/FAMEX campaigns in their derivation. 


\section{Data and Methods}

The data used in this study consist of previously unpublished multibeam bathymetric, sidescan and total field magnetic data collected in April and May 2002 during the FAMEX and BART campaigns of the N/O L'Atalante. Additional marine magnetic data in the area of the MSS were obtained from the National Geophysical Data Center's GEODAS database. The ship tracks along which the data were collected are illustrated in Figure 3.

The multibeam bathymetric and sidescan image data were collected with a dual Simrad EM-12 multibeam system and the raw data was processed using the CARAIBES software while onboard by IFREMER technicians to produce a 200 x 200 meter grid of bathymetric values (Figure 4). The sidescan data was processed into a $50 \mathrm{~m}$ x $50 \mathrm{~m}$ grid of seafloor backscatter amplitudes (Figure 5).

Total field, marine magnetic data collected along crossings of the MSS were modeled to determine average spreading rates. The modeling used the 2-D magnetic modeling program coded by J.L. LaBrecque, which is based on the fast Fourier transform method of Schouten and McCamy (1972). The time scale used is that of Cande and Kent (1995). In all models the magnetized layer is assumed to be 500 meters thick having a time invariant strength of magnetization equal to $0.01 \mathrm{EMU} / \mathrm{cm}^{3}$. The depth in meters below the sea surface to the top of the magnetized layer, $\mathrm{D}$, is assumed to follow the relationship $\mathrm{D}=2500.0+350.0 \sqrt{ } \mathrm{t}$, where $\mathrm{t}$ is the age of the crust in million years. A transition zone $1.0 \mathrm{~km}$ wide is assumed between each reversal. Present day inclinations and 
declinations are obtained from Merrill and McElhinny (1983). The remnant inclination is assumed to be identical to the present day inclination, and the remnant declination is assumed to be zero.

\section{Morphology}

The gross morphology of the MSS as indicated by the new data (Figure 6) is generally consistent with that presented previously (Bandy, 1992; Bandy and Hilde, 2000), although the details and locations are more clearly defined. The major morphotectonic elements include the Rivera Transform, the Rivera Fracture Zone, the Paleo-Rivera Transform, the MSS, and the outer and inner tectonic pseudofaults and outer and inner rough-smooth boundaries associated with the MSS propagator. The area north of $18^{\circ} \mathrm{N}$ exhibits eight major morpho-tectonic zones. These are: (1) the zone of lithosphere formed entirely along the MSS (Zone A, figure 6), (2) the outer pseudofault zone (Zone B), (3) the inner pseudofault zone (Zone B'), (4) the zone of undisturbed seafloor (Zone C) of the Pacific plate west of the MSS propagator, (5) a zone (Zone D) of disrupted old crust located just south of the Rivera Transform, (6) a previously unrecognized zone (Zone E) of highly sheared crust in the overlap zone, (7) the southern Rivera plate shear zone (Zone F) previously recognized by Lonsdale (1995), and (8) the transform tectonized zone of the eastern end of the Rivera Transform (Zone G).

\subsection{MSS propagator system}


The terminology used herein is that of the "type example" of a ridge propagator presented by Kleinrock and Hey (1989a). Briefly, their model consists of the propagating-ridge axis flanked to either side by lithosphere formed entirely at the propagating ridge (the 'propagator lithosphere zone'). This newly formed lithosphere is separated from the older, pre-existing, lithosphere (through which the ridge propagated) by two zones of disrupted lithosphere; namely, the 'outer pseudofault zone' located farthest from the dying ridge, and the 'inner pseudofault zone' located closest to the dying ridge. These pseudofault zones are bounded by the 'full rate pseudofault' located closest to the propagator and the 'tectonic pseudofault' located farthest from the propagator. Herein we will the term 'rough-smooth' boundary in place of the 'full rate pseudofault' of Kleinrock and Hey (1989a) since it is not possible to establish the point at which spreading commenced at the full spreading rate. The MSS propagator lends itself to this modification as the newly generated crust is sediment free (i.e. rough seafloor) and gives rise to strong backscatter amplitudes, whereas the adjacent older crust is covered by sediments (smooth-seafloor) and gives rise to weak backscatter amplitudes as is clearly observed on the sidescan mosaic

(Figure 5). Thus, the psuedofault zones are taken to lie between the rough-smooth boundaries and the tectonic pseudofaults.

\subsubsection{Propagator Lithosphere Zone and MSS Axis}

The propagator lithosphere zone (Zone A on Figure 6) is an $\sim 35 \mathrm{~km}$ wide zone of rough, high backscatter amplitude (sediment free), seafloor bounded to either side by zones of low backscatter amplitude (sediment covered) seafloor. The boundaries between 
these zones, most easily defined on the sidescan image (Figures 5 and 6), are the 'rough-smooth boundaries'. The width of this zone is constant from its intersection with the Rivera Transform to $18^{\circ} 07^{\prime} \mathrm{N}$; south of which it begins to narrow.

The axis of the MSS (Figure 4) lies in the center of the propagator lithosphere zone indicating that, recently, symmetrical seafloor spreading has been occurring along the MSS. Between its intersection with the Rivera Transform at $18^{\circ} 30.9^{\prime} \mathrm{N}, 106^{\circ} 16.8^{\prime} \mathrm{W}$ and $18^{\circ} 02^{\prime} \mathrm{N}$ (the southern limit of our data coverage), the axis consists of two segments that are offset $1.6 \mathrm{~km}$, in a right-stepping manner, at $18^{\circ} 18^{\prime} \mathrm{N}$. North of $18^{\circ} 23.4^{\prime} \mathrm{N}$, the northern ridge segment is marked by a narrow central volcanic ridge located within an axial graben (Figure 7) which increases in width as it approaches the Rivera Transform. Between $18^{\circ} 29.2^{\prime} \mathrm{N}$ and $18^{\circ} 18^{\prime} \mathrm{N}$ the ridge is oriented $\mathrm{N} 04^{\circ} \mathrm{E} \pm 2^{\circ}$ (all azimuth uncertainties reported herein are measured graphically from the data) and bends westward north of $18^{\circ} 29.2^{\prime} \mathrm{N}$. Between $18^{\circ} 23.4^{\prime} \mathrm{N}$ and $18^{\circ} 18^{\prime} \mathrm{N}$, the central volcanic ridge is not observed.

The southern ridge segment extends from the $18^{\circ} 18^{\prime} \mathrm{N}$ offset to at least $18^{\circ} 02^{\prime} \mathrm{N}$ (the southern limit of our data coverage). Between $18^{\circ} 18^{\prime} \mathrm{N}$ and $18^{\circ} 09^{\prime} \mathrm{N}$ the axis is marked by two small closed basins (Figure 4 ). Between $18^{\circ} 09^{\prime} \mathrm{N}$ and $18^{\circ} 02^{\prime} \mathrm{N}$, a narrow central volcanic ridge is again present. Here the ridge is oriented $\mathrm{N} 01^{\circ} \mathrm{W} \pm 1^{\circ}$.

\subsubsection{Area West of the MSS Axis}


The outer pseudofault zone associated with the MSS propagator is a zone of high relief seafloor located west of the outer rough-smooth boundary. We locate the western boundary (the outer tectonic pseudofault) of this zone along a prominent, continuous, down to the east, bathymetric escarpment (Figures 4, 5 and 6). The relief along this escarpment increases southward from less than 100 meters in the north near the Rivera Transform to more than 1,000 m near the point to the south where it merges with the outer rough-smooth boundary. The structural features within the outer pseudofault zone exhibit N-S orientations similar to that of the undisrupted seafloor abyssal hill fabric of the Pacific plate to the south. Of particular importance is a very high relief bathymetric ridge (Figure 8), herein termed the "west ridge", located within the outer pseudofault zone, adjacent to the outer tectonic pseudofault. Dredging conducted during the project MARTIC05, conducted in January 2006 aboard the EL PUMA, indicate that the seafloor along the base of the east and south flanks of this ridge is covered by extensive talus deposits consisting of small (up to $6 \mathrm{~cm}$ in length) angular basalt fragments, no rocks larger than $6 \mathrm{~cm}$ were recovered. Similar talus deposits have been observed within the outer pseudofault zones in other propagator systems (Kleinrock and Hey, 1989a) where the seafloor is predominantly comprised of older crust. Unfortunately, these fragments appear unsuitable for age dating so it is unclear whether this ridge is comprised of newly generated lithosphere or if it is a piece of older lithosphere, formed prior to the onset on propagation of the MSS. As will be discussed later, this uncertainty complicates the analysis of the age of initiation of seafloor spreading at the MSS.

The morphology and magnetic lineations of Zone C (Figures 2, 6 and 8), located west of the outer tectonic pseudofault, south of $18^{\circ} 20^{\prime} \mathrm{N}$, indicates that the lithosphere contained within this zone is the older, undisrupted lithosphere formed prior to the 
propagation of the MSS; consistent with the "type" model of Kleinrock and Hey (1989a). In contrast, although the prominent escarpment marking the outer tectonic pseudofault continues north of $18^{\circ} 20^{\prime} \mathrm{N}$, the lithosphere west of this escarpment (in Zone D) is highly disrupted, contrary to the "type model". Within Zone D, the seafloor exhibits abundant high spatial frequency, circular seafloor features (Figure 8) which are interpreted as being the result of intense, diffuse volcanic activity within the zone. To the west, the southern boundary of this zone is quite sharp, marked by a prominent, down-to-the north escarpment. South of this escarpment, in the Moctezuma trough, the seafloor is unaffected by this volcanism. Thus, this deformation must have occurred after the Moctezuma trough formed. The magnetic lineation terminations (Figure 2) against the trough in this area indicate that, in this area, the Moctazuma trough formed at about $3 \mathrm{Ma}$ (Anomaly 2A2) (Mammerickx et al., 1988).

South of $18^{\circ} 07^{\prime} \mathrm{N}$, the outer tectonic pseudofault and the rough-smooth boundaries merge (Figure 6) resulting in the lack of an outer pseudofault zone. This observation contrasts with the "type example" which predicts that the pseudofault zones form by "diffuse (slow) lithospheric extension ahead of the propagator". The lack of a zone of diffuse extension south of $18^{\circ} 06^{\prime} \mathrm{N}$ is puzzling. Perhaps it indicates a period of rapid southward propagation, or it might be related somehow to the presence of a small relay-spreading-center located between the MSS and the failing ridge segment to the east (Bandy and Hilde, 2000; Baker et al., 2001).

\subsubsection{Area East of the MSS Axis}


The morphology of the inner pseudofault zone located east of the MSS axis is more complicated as is commonly the case in propagator systems. These complications arise mainly by deformation (e.g. shearing, block rotations and uplift) of the older lithosphere within the overlap zone as it is transferred from one plate to the other (Kleinrock and Hey, 1989b). Herein, we define the inner pseudofault zone (Figures 6 and 9) associated with the MSS propagator by the difference in the orientation of the seafloor structures within the pseudofault zone relative to that observed within the propagator lithosphere zone. Within the inner pseudofault zone the seafloor fabric exhibits prominent NE-SW lineaments, which are completely absent to the west within the propagator lithosphere zone where the seafloor fabric trends N-S. The NE-SW fabric of the seafloor east of the pseudo fault is consistent with a rotation of older lithosphere, originally with $\mathrm{N}-\mathrm{S}$ oriented fabric, within a left stepping ridge overlap zone. Thus, like the "type example", this zone is most likely comprised, for the most part, of older lithosphere that was not created at the MSS. The inner tectonic pseudofault is difficult to locate conclusively, and the two previously proposed (Bandy, 1992) locations remain valid. The easternmost of these locations is, unfortunately, only imaged near its intersection with the paleo-Rivera Transform (at $105^{\circ} 41^{\prime} \mathrm{W}$ ) where it is marked by a narrow, $500 \mathrm{~m}$ deep, N-S elongate, sediment filled trough (Figure 9). The western possible location is also marked by a deep, sediment filled trough, elongated NE-SW, which intersects the paleo-Rivera transform at a closed basin located at $105^{\circ} 48^{\prime} \mathrm{W}$. The inner rough-smooth boundary merges with the NE-SW orientated trough at $18^{\circ} 11^{\prime} \mathrm{N}$. If this trough is the inner 
tectonic pseudofault, then the psuedofault zone is not found south of $18^{\circ} 11$ 'N, consistent with that observed on the west side of the propagator.

The new data just barely images a previously unrecognized zone of intense shearing (Zone E, figure 9), which appears to also affect the southernmost part of Zone B'. More data is needed to understand the tectonic significance of Zone E; however, the disruption of the southern part of Zone B' indicates that Zone E developed after the ridge propagated to this area.

\subsection{Rivera Transform/Fracture Zone/Paleo-Transform System.}

The Rivera Transform-Rivera Fracture Zone-paleo-Rivera Transform system is of particular importance for analyzing the relative motions between the Pacific and Rivera plates. Specifically, the transform and fracture zone can be used to determine the recent Rivera-Pacific relative motion; whereas, the paleo-transform can be used to infer either past plate motion directions or the style

of deformation occurring in this area since the time that the paleo-transform was rendered inactive. It is important to understand that the paleo-transform was once part of the Rivera Transform and was abandoned when the locus of seafloor spreading relocated westward to the MSS. The Rivera Fracture Zone was formed subsequently due to seafloor spreading along the MSS and is presently located between the now active Rivera Transform and the paleo-Rivera Transform (Figure 4).

\subsubsection{Rivera Transform}


Principle transform displacement zones (PTDZs), defined as the "locus of [present-day] strike-slip motion" (Macdonald et al., 1986), are commonly marked by a narrow, linear bathymetric trough (e.g. Pockalny et al., 1997). Similarly, the PTDZ of the Rivera transform east of the MSS is remarkably narrow ( $\sim \mathrm{km}$ wide) and well defined (Figure 10). It consists of two long, narrow, continuous troughs that generally lie within a broader (4-6 km wide), high-relief, valley (also see Figure 5); the transform tectonized zone (TTZ). The trough to the west (Segment G) lies between $107^{\circ} 09^{\prime} \mathrm{W}$ and $106^{\circ} 47^{\prime} \mathrm{W}$. The trough to the east lies between $106^{\circ} 54^{\prime} \mathrm{W}$ (the west end of segment F) and the MSS. These two troughs overlap each other between $106^{\circ} 54^{\prime} \mathrm{W}$ and $106^{\circ} 47^{\prime} \mathrm{W}$. The westernmost trough shows two orientations. Between $107^{\circ} 09^{\prime} \mathrm{W}$ and $106^{\circ} 54^{\prime} \mathrm{W}$ (segment G) it is remarkably straight, orientated $108^{\circ} \pm 1^{\circ}$ (all transform azimuth uncertainties reported herein are measured graphically from the data). Between $106^{\circ} 54^{\prime} \mathrm{W}$ and its terminus at $106^{\circ} 49^{\prime} \mathrm{W}$ (segment $\mathrm{F}$ ) the trough is oriented $105^{\circ} \pm 2^{\circ}$. The trough marking the eastern part of the PTDZ is more sinuous and curved than the trough to the west. Between $106^{\circ} 54^{\prime} \mathrm{W}$ and $106^{\circ} 30^{\prime} \mathrm{W}$ the trough is located along the southern margin of a broad basin. In the western part of the basin (segment E) the trough trends $98^{\circ} \pm 2^{\circ}$; whereas to the east (segment D) it trends $103^{\circ} \pm 2^{\circ}$. Between segments D and C, the active transform undergoes a slight northward deflection. Between $106^{\circ} 27^{\prime} \mathrm{W}$ and $106^{\circ} 23^{\prime} \mathrm{W}$ (segment C) the trough associated with the Rivera Transform trends $100^{\circ} \pm 3^{\circ}$.

The prominent transform valley marking the TTZ terminates at $106^{\circ} 22^{\prime} \mathrm{W}$, west of the MSS-RT intersection (Figure 7). However, the trough-and-ridge morphology associated with the PTDZ continues eastward. It is important to note that the PTDZ is 
clearly observed to climb up along the face of the northern escarpment as it approaches its junction with the MSS; the junction being located at $18^{\circ} 30.9^{\prime} \mathrm{N}, 106^{\circ} 16.8^{\prime} \mathrm{W}$ (Figure 11). This is contrary to most intuition as typically the transform would be expected to run along the base of the escarpment (Wilson and DeMets, 1998). The orientation of the transform is not entirely clear along segment B. If the transform runs through the center of the trough (Figure 11) located on the north side of the low relief ridge, then the transform has an orientation of $96^{\circ} \pm 4^{\circ}$ between $106^{\circ} 25.8^{\prime} \mathrm{W}$ and $106^{\circ} 20^{\prime} \mathrm{W}$ (segment $\mathrm{B}$ ). The transform is not associated with any clear bathymetric trough along segment $\mathrm{A}$. In contrast, the sidescan image indicates an orientation of $100^{\circ} \pm 2^{\circ}$ for segment $\mathrm{B}$ with an abrupt change to $97^{\circ} \pm 4^{\circ}$ along segment $\mathrm{A}$.

\subsubsection{Rivera Fracture Zone}

The Rivera Fracture Zone lies east of the axis of the MSS between $106^{\circ} 16.8^{\prime} \mathrm{W}$ and $106^{\circ} 01^{\prime} \mathrm{W}$ (Figure 9). Between $106^{\circ} 16.8^{\prime} \mathrm{W}$ and $106^{\circ} 06.6^{\prime} \mathrm{W}$ the precise orientation of the fracture zone is unclear due to the westward bending of the abyssal hill fabric as it approaches the fracture zone; the abyssal hill fabric riding up the escarpment. However, between $106^{\circ} 06.6^{\prime} \mathrm{W}$ and $106^{\circ} 01^{\prime} \mathrm{W}$ the fracture zone is well defined by a prominent, down to the south, bathymetric escarpment, and we place the fracture zone at the base of this escarpment. The orientation of the base of this escarpment is $95^{\circ} \pm 3^{\circ}$. A closed basin is located at the eastern terminus of the fracture zone, which appears to correlate with the basin located along the Rivera Transform at $106^{\circ} 36^{\prime} \mathrm{W}$ (Figure 10 ). 
If so, then these two basins mark the location of the initiation of spreading along the MSS and, further, may be conjugate points which need to be brought back together in plate reconstructions.

\subsubsection{Paleo-Rivera Transform}

The paleo-Rivera Transform (Figures 2 and 9) is a high relief, sinuous bathymetric structure that extends from the eastern end of the Rivera Fracture Zone to the tip (not imaged by the new data) of the failed rift located at $105^{\circ} 25^{\prime} \mathrm{W}$ (Bourgois et al., 1988 ; Bandy, 1992). The sinuosity of this structure appears to be due to a series of $\sim 120^{\circ}$ oriented, narrow troughs that are deflected northward as one proceeds eastward along the paleo-transform. The sidescan image shows low reflectivity within these narrow troughs indicating that they are old structures. Three isolated, sediment filled (low seafloor-backscatter amplitudes) basins are located at the ends of these troughs, in the area where these troughs are deflected northward (Figure 9). The overall orientation of the paleotransform is $112^{\circ}$; roughly $20^{\circ}$ clockwise of the orientation of the Rivera Fracture Zone.

\section{Discussion}

The new data permit us to resolve several differences existing between the various databases previously used to determine the recent motion of the Rivera plate relative to the Pacific plate. These include (1) differences in the location of the point of intersection 
of the MSS and Rivera Transform, (2) differences in the orientation of the Rivera Transform adjacent to the MSS, (3) differences as to if spreading rates determined along the MSS as well as earthquake slip vectors for events occurring along the Rivera Transform should be included in the plate motion database, and (4) differences as to if there has been a recent change in Rivera-Pacific relative plate motion.

\subsection{Rivera Transform-MSS Intersection/ Rivera Transform Orientation}

Concerning the location of the junction of the Rivera Transform and MSS intersection, the new data clearly shows that the PTDZ of the Rivera Transform climbs up the northern transform wall as it approaches its intersection with the MSS at $18^{\circ} 30.9^{\prime} \mathrm{N}$, 106 $16.8^{\prime} \mathrm{W}$; thus, confirming the location proposed by Bourgois et al. (1988), Bandy (1992) and Michaud et al. (1996). The PTDZ does not lie at the base of the northern escarpment as proposed by Wilson and DeMets (1998).

In contrast, although the new data confirms the location of the Rivera Transform at its eastern end, the data is contradictory as to its precise orientation. If the transform runs through the center of the trough (Figure 11) located on the north side of the low relief ridge as proposed by Bourgois et al. (1988), then the transform has an orientation of $96^{\circ} \pm 4^{\circ}$ between $106^{\circ} 25.8^{\prime} \mathrm{W}$ and $106^{\circ} 20^{\prime} \mathrm{W}$

(segment B). In contrast, the sidescan image indicates an orientation of $100^{\circ} \pm 2^{\circ}$ for segment B with an abrupt change to $97^{\circ} \pm 4^{\circ}$ along segment A. This discrepancy between the two data sets is at first puzzling. However, a close examination of the two data sets shows 
that the high reflectivity lineament observed on the sidescan data originates from the north flank of the low relief ridge located on the south side of the trough, and not from the trough itself. Thus, two reasonable interpretations exist for the orientation of the transform along segment $\mathrm{B}$; namely, $100^{\circ} \pm 2^{\circ}$ or $96^{\circ} \pm 4^{\circ}$. However, given the continuity of the high amplitude lineament on the sidescan image, and the broad-short geometry of the trough, we favor a $100^{\circ} \pm 2^{\circ}$ orientation for segment $\mathrm{B}$.

\subsection{Spreading rates along the MSS: reliable indicators of Rivera-Pacific motion?}

The seafloor magnetic lineations in the area of the MSS (Figure 12) in conjunction with the new seafloor morphology data better constrain when seafloor spreading was initiated along the MSS.

The new data clearly indicates that Anomaly J (polarity Chron 1r.1n in the terminology of Cande and Kent, 1995) is absent along the MSS. To show this, we begin by constructing a model (Model-1, Figure 13) in which Anomaly J is assumed to be present, similar to that presented by DeMets and Wilson (1997), and compare it to the magnetic anomalies observed along profile 3 (see Figure 3 for profile location). The full-spreading rate was chosen to be consistent with that expected for Rivera-Pacific relative motion in this area. Clearly, the model poorly fits the observed data west of the ridge axis. More importantly, the magnetic high west of the ridge axis, which was previously picked as Anomaly $\mathrm{J}$, lies west of the outer tectonic pseudofault and is thus an older anomaly (perhaps Anomaly $2 \mathrm{~A}_{1}$; polarity Chron $\left.2 \mathrm{An} .1 \mathrm{n}\right)$. East of the ridge axis, the fit between the model and observed data is better, however, the magnetic high taken previously to be Anomaly $\mathrm{J}$ lies in the area of the inner pseudofault zone where the seafloor fabric has been 
rotated clockwise. This rotation is a clear indication that the majority of the lithosphere in this area was not formed at the MSS. Thus, we conclude from these observations that this anomaly is also an older anomaly and cannot be Anomaly $\mathrm{J}$.

The observed magnetic data exhibits what we feel is a very well developed expression of the central anomaly located between the points A and B shown on Figure 13. Given this, and given the poor fit of the above model with the observed data west of the ridge axis, we have constructed a second model (Model-2, Figure 13) in which the spreading rate is not constrained to be similar to the expected rate of Rivera-Pacific motion. A very good fit is obtained employing a full spreading rate since $0.78 \mathrm{Ma}$ of $4.2 \mathrm{~cm} / \mathrm{yr}$.

However, we again conclude that Anomaly $\mathrm{J}$ is not present since the anomaly modeled as Anomaly $\mathrm{J}$ east of the MSS again lies within the zone of rotated seafloor fabric.

The results of Model-2 raises the obvious question that if the anomaly associated with the West Ridge is not Anomaly J, what is it? The West Ridge could be a piece of old lithosphere that is now located within the outer pseudofault zone and the anomaly is an old anomaly. If so, then either seafloor spreading was initiated during the middle part of the Brunhes, which seems unlikely given the magnetic lineations present along the failed rift to the east (Figure 2), or the MSS is not a Rivera-Pacific boundary. In support of the latter possibility, it has been proposed (e.g., Mammerickx and Carmichael, 1989; Michaud et al., 1997) that the MSS may not separate rigid parts the Rivera and Pacific plates as is commonly accepted, and some divergence could be accounted for by block rotations in the crust east of the MSS as is discussed below. 
Alternatively, the West Ridge may consist of young lithosphere and that the poor fit between the observed and modeled anomalies shown in Model-1 is the result of a complicated spreading history. The study of Crane (1979) provides one possible scenario to account for the poor fit. In that study it was proposed that seafloor accretion within the Galapagos propagator may not be confined to one location, but may instead occur at several distinct locations, each having a distinct spreading rate. Where the accretion is slow, a high relief volcanic ridge could develop, whereas no high relief feature would develop where accretion is fast. Thus, if the west ridge is comprised of young lithosphere, it is conceivable that accretion in this area is occurring or has occurred at two distinct, but not necessarily contemporaneous, locations; fast accretion at the MSS axis and slow accretion at the west-ridge (Figure 14). This explanation is appealing in that it explains the poor fit of Model-1 to the observed magnetic data, while maintaining a combined spreading rate more in line with that expected for Rivera-Pacific relative motion in this area. It would also explain the presence of the well-defined, but surprisingly narrow, central anomaly associated with the MSS. As pointed out by one of the reviewers, the West Ridge might be the site of the initial extension at the beginning or slightly prior to the formation of the propagator.

Given the above uncertainties, spreading rates calculated at the MSS and the orientation of the MSS presently should not be used in the construction of Rivera-Pacific relative plate motion models. Central to these uncertainties is the age of the West Ridge. Currently, plans are being made to undertake further dredging over the West-Ridge to obtain seafloor samples that are suitable for age dating. 


\subsection{Possible biases in earthquake data along the Rivera Transform}

Earthquake slip vectors located along transform faults have been commonly used in plate motion determinations. However, studies (see Gordon (1995) for a review) have shown that systematic biases (e.g. in the epicenter locations and slip vector orientations) can exist in the earthquake data that could adversely affect plate motion determinations. Specifically, it has been observed that slip vectors of earthquakes occurring along right-slipping transforms are a few degrees clockwise of transform azimuths, whereas, they are counterclockwise of transform azimuths for left-slipping transforms (e.g., Gordon, 1995). Second, the epicenters of events occurring along the Middle America Trench off Mexico calculated from teleseismic recordings are shifted about 35 km towards the northeast relative to epicenters determined using local stations (Singh and Lermo, 1985). Thus, the logical question is 'are these biases present

in the survey area?' If they do exist then earthquake slip vectors for events occurring along the Rivera Transform should not be used in the derivation of Rivera-Pacific relative plate motions.

Figure 10 illustrates the earthquake focal mechanisms (Harvard CMT database) of events occurring along the Rivera Transform between $106^{\circ} 20^{\prime} \mathrm{W}$ and $107^{\circ} 15^{\prime} \mathrm{W}$. No focal mechanisms have been reported for events occurring between the MSS and $106^{\circ} 20^{\prime} \mathrm{W}$. The number in parentheses is the slip direction (degrees clockwise from north) corresponding to the nodal plane oriented in the general direction of the Rivera Transform. A general northward bias is clearly present in the centroid moment locations. The magnitude of this bias (calculated as the perpendicular distance from the epicenter to the transform) is as great as $40 \mathrm{~km}$, but for the most part is between 20 and $30 \mathrm{~km}$, fairly consistent with that observed (35 km) for other Mexican earthquakes. In contrast, the 
majority of the slip vectors lie within the range of transform azimuths observed within this area, which suggests that if a bias in the slip vectors is present, it is small. Unfortunately, the large uncertainty in epicenter locations in conjunction with the fact that the Rivera-Pacific Euler pole lies close to this area prevents a more detailed analysis of the presence of this bias. However, the location bias alone dictates that, here, the earthquake slip vectors should not be used to determine the Rivera-Pacific Euler pole.

\subsection{The Paleo-Rivera Transform: Plate Motion Change or Deformation?}

Changes in relative plate motions commonly result in the abandonment and relocation of the PTDZ of oceanic transforms, the bathymetric expression of the abandoned PTDZ being similar to the active PTDZ. An excellent example of this is found in the area of the Siqueiros Transform where four abandoned PTDZ have been observed (Pockalny et al., 1997). Also, changes or bends (Figure 15) in the orientation of fractures zones have been taken as indicators of past plate motion changes (e.g. Morgan, 1968; LePichon, 1968; Rabinowitz and Purdy, 1976).

Such a change is observed east of the MSS where a roughly $20^{\circ}$ bend occurs at the junction of the paleo-Rivera Transform and the Rivera Fracture Zone (Figure 9). This bend led to the proposal (Bandy et al., 1998b) of a large counterclockwise reorientation of Rivera-Pacific motion at the time of formation of the MSS. However, the new bathymetry data collected along the Rivera Transform between the MSS and $107^{\circ} 15^{\prime} \mathrm{W}$, shows no bathymetric features that clearly can be related to a large change in plate motion direction. Thus, the difference in orientations of the paleo-Rivera Transform and the Rivera Fracture Zone cannot be the result of a large change 
in plate motion as previously proposed. Now, if there was no plate motion change at the time of initiation of the MSS then plate tectonic theory dictates that the orientation of the paleo-Rivera Transform and the Rivera Fracture Zone should be the same near their juncture unless they have subsequently been deformed (Figure 15). Consequently, the observed difference in orientations must be due to deformation of the paleo-transform after it was abandoned.

The difference in orientations of the paleo-Rivera Transform and the Rivera Fracture Zone, as well as the present-day 'zig-zag' morphology of the paleo-transform can arise from clockwise rotation of crustal blocks, the classical "bookshelf" rotation mechanism of Freund (1974), located south of the paleo-Rivera Transform (Figure 15). Specifically, as the MSS propagated south, in conjunction with the southward cessation of spreading along the relict ridge to the east, a right lateral shear zone would develop within the overlap zone between the ridge segments. This would produce a clockwise rotation of crustal blocks within the overlap zone (see Kleinrock and Hey (1989b) for a more detailed explanation of this process). As illustrated in Figure 15, this would produce the observed (1) segmentation of the paleo-transform, (2) clockwise rotation of each segment relative to that expected if the paleo-transform was undeformed, and (3) northward deflection of adjacent segments as one goes eastward along the paleo-transform (after rotation the paleo-transform is the trace of the northern boundary of the rotated blocks).

In summary, the new data does not support a recent major change in the orientation of Rivera-Pacific relative motion in this area. It is also worth noting that such block rotations would produce an east-west elongation of the lithosphere which would reduce 
the amount of divergence along the MSS during the past $0.78 \mathrm{Ma}$. Unfortunately, a more quantitative examination of this cannot be done at present in that only the northwest portion of the old overlap zone was imaged by the new data.

\section{5. Limitations of plate motions predicted from existing Rivera-Pacific Euler poles}

To evaluate the limitations of the existing models for accurately predicting the relative motion of the Rivera plate with respect to the Pacific plate in the study area, and to investigate the possible presence of biases in the various models, we plot (Figure 16) the differences, or residuals, between the observed azimuths of the Rivera transform with the directions of relative motion predicted from the best-fit poles of the various models at the center of transform segments A, B, C, D, F, and G and at the eastern end of the Rivera Fracture Zone where the fracture zone is marked by the prominent escarpment. Negative residuals indicate that the predicted values are counterclockwise of the observed values. The vertical lines on figure 16 are the assigned uncertainties in the orientations of the transform segments.

Herein, we define the accuracy of the model as "a measure of how close the experiment [model] comes to the true value" (Bevington, 1969). The basis for our analysis is the convention of Bevington (1969) that the central tendency or mean (or in our case the best-fit pole of the various models) can be "considered to be the best estimate that can be made of the "true" value....". Further, the accuracy of a model "is generally dependent on how well we can control or compensate for systematic errors. These are the errors

which will make our results different from the "true" values." It follows therefore that (1) the relative accuracy of the predictions of 
the existing plate motion models can be deduced from the difference between the "true" value (in our case the observed azimuths) and the best estimate of the "true value" (in our case the azimuth determined from the best-fit pole of the various models), and that (2) systematic errors can be inferred from these differences.

For the study area, the plate motion orientations predicted by the best-fit poles of the models of Bandy et al. (1998a), DeMets and Traylen (2000), Lonsdale (1995) and DeMets and Stein (1990) lie outside the uncertainties of the observed azimuths ("true" values) at the majority of the transform/fracture zone segments. Thus, the best-estimates of these models do not coincide with the "true" values in the majority of the cases. In contrast, the plate motion orientations predicted by the best-fit poles of the models of Bandy et al. (1992), DeMets and Wilson (1997), and poles B2007-1 and B2007-2 of Bandy et al (2007) lie within the uncertainties of the observed azimuths at the majority of the transform/fracture zone segments. Thus, under the convention of Bevington (1969), the latter four poles can be considered are being fairly accurate predictions of the Rivera-Pacific relative plate motion, at least within the study area.

Of notable interest is the observation made by one of the reviewers that the residual values of all but one pole (B2007-2) contain a systematic bias; namely, that the residuals increase eastward along the transform/fracture zone. The exact origin of this bias is not known, however, the only difference between pole B2007-1 and pole B2007-2 is the orientation of the Rivera Transform where it intersects the Rivera Rise, west of the study area. Thus, the source of the bias may stem from the inclusion in the plate motion 
database of an erroneous orientation of the Rivera transform in that area. Further investigation of this possibility is left for a future paper.

\subsection{Initiation of Rifting.}

Although it has no obvious significance to the determination of Rivera-Pacific relative motion, the anomalous deformation in zone D (Figure 6) west of the MSS is worth noting in that the outer tectonic pseudofault may not lie along the prominent bathymetric escarpment north of $18^{\circ} 20^{\prime} \mathrm{N}$ but, instead, further to the west (one option presented in Bandy (1992), Figure 2). However, this is an extremely wide pseudofault zone, about $70 \mathrm{~km}$, which seems unlikely. Alternatively, the "type" model of Kleinrock and Hey (1989a) deals only with the morphotectonic elements produced as the ridge propagates through older lithosphere; it does not specifically deal with elements produced during the initial formation of the propagator. As the MSS was initiated at the Rivera Transform, the anomalous deformation observed in zone D, may reflect the initial tectonic environment leading to rift formation. The morphologic features present in zone D suggest diffuse volcanism, possible related to intense fracturing of the lithosphere. This deformation is consistent with the proposal of Mammerickx and Sandwell (1986) that the formation of a propagating rift begins with a localized stretching and thinning of the lithosphere, perhaps as the result of an underlying thermal anomaly, which is then followed by the development and subsequent propagation of the rift itself. Further investigation of zone D may help in understanding the processes involved in the initial rifting phase of rift propagation. 


\section{Conclusions}

The main conclusions of this study are:

(1) The Moctezuma Spreading Segment exhibits morphotectonic elements typical of a southward propagating ridge. The axis of the MSS north of $18^{\circ} 02^{\prime} \mathrm{N}$ consists of two segments that are offset $1.6 \mathrm{~km}$, in a right-stepping manner, at $18^{\circ} 18^{\prime} \mathrm{N}$. The northern and southern segments trend $\mathrm{N} 04^{\circ} \mathrm{E} \pm 2^{\circ}$ and $\mathrm{N} 01^{\circ} \mathrm{W} \pm 1^{\circ}$, respectively. Seafloor spreading along the MSS was most likely initiated sometime during the later part of polarity Chron $1 \mathrm{R}$ (between 0.78 to $0.9 \mathrm{Ma}$ ). The uncertainty in the age of the lithosphere comprising the West-Ridge prevents a conclusive determination of the spreading rate at the MSS. If the west-ridge is a piece of trapped, old, lithosphere then the spreading rate is $\sim 4.2 \mathrm{~cm} / \mathrm{yr}$, much slower than expected for Rivera-Pacific motion in this area. If the west ridge marks a second spreading center within the MSS system, then the combined spreading rate is $\sim 7 \mathrm{~cm} / \mathrm{yr}$, consistent with that previously proposed for Rivera-Pacific relative motion in this area. Until the age of the west-ridge is resolved, one should not use spreading rates calculated along the MSS to derive models of Rivera-Pacific relative motion.

(2) The PTDZ of the Rivera Transform east of $107^{\circ} 10^{\prime} \mathrm{W}$ consists of two continuous faults which overlap each other between $106^{\circ} 54^{\prime} \mathrm{W}$ and $106^{\circ} 47^{\prime} \mathrm{W}$. The azimuth of the PTDZ becomes progressively rotated counterclockwise eastward along the transform; the azimuth being $108^{\circ} \pm 1^{\circ}$ to the west and between $97^{\circ}$ and $100^{\circ}$ to the east. 
(3) West of $106^{\circ} 22^{\prime} \mathrm{W}$, the PTDZ of the Rivera Transform lies within a deep transform valley. East of $106^{\circ} 22^{\prime} \mathrm{W}$, the deep transform valley terminates and the PTDZ climbs up along the face of the northern transform wall as it approaches its junction with the MSS at $18^{\circ} 30.9^{\prime} \mathrm{N}, 106^{\circ} 16.8^{\prime} \mathrm{W}$.

(4) The abrupt change in the orientations of the Rivera Fracture Zone and the paleo-Rivera Transform at their juncture is proposed to be the result of clockwise rotation of crustal blocks located south of the paleo-transform, and not the result of an abrupt change in Rivera-Pacific relative plate motion at the time of formation of the MSS as previously proposed.

(5) The centroid moment location of earthquakes occurring along the eastern end of the Rivera Transform show a large (20 to $30 \mathrm{~km})$ bias. The direction of the bias is generally to the north, but its exact direction is uncertain. This bias needs to be identified and removed if earthquake slip vectors are to be used to derive Rivera-Pacific relative motions.

(6) The comparison between the observed orientations of the Rivera Transform/Rivera Fracture Zone and their orientations predicted by previous Rivera-Pacific relative plate motion models shows that: 
(a) the models of Bandy (1992), DeMets and Wilson (1997), and the two models of Bandy et al. (2007) provide for a fairly accurate representation of the orientation of Rivera-Pacific relative plate motion, at least within the study area and,

(b) A systematic bias, perhaps related to uncertainties in the orientation of the Rivera transform near its intersection with the Rivera Rise, exits in the relative motions predicted by all of the existing Rivera-Pacific plate motion models with the exception of model B2007-2; the bias being an eastward increase in the residuals (predicted minus the observed azimuths).

(7) A zone of diffuse volcanism is located west of the outer tectonic pseudofault, just south of the Rivera Transform. This zone may reflect the tectonic environment present during the initial formation of the propagating rift.

Acknowledgments. We thank the captain and crew of the R/V L'Atalante for their assistance during the cruise and IFREMER's multibeam technicians for the processing of the multibeam bathymetric and reflectivity data. We also thank two anonymous reviewers whose comments improved the manuscript. The BART campaign was funded by CONACyT grant 36681-T. The FAMEX campaign was funded by the Centre National de la Recherche Scientifique (CNRS). Additional funding was provided by CONACyT grant \#50235 and UNAM/DGAPA grants \#IN104707 and IN116505. 


\section{References}

Baker, E.T., Cormier, M.-H., Langmuir, C.H., Zavala, K., 2001. Hydrothermal plumes along segments of contrasting magmatic influence, $15^{\circ} 20^{\prime}-18^{\circ} 30^{\prime} \mathrm{N}$ East Pacific Rise: Influence of axial faulting. Geochemistry, Geophysics Geosystems 2, Paper \#2000GC000165, Sept. 24.

Bandy, W.L., 1992. Geological and geophysical investigation of the Rivera-Cocos plate boundary: Implications for plate fragmentation. Ph.D. dissertation, 195pp., Tex. A\&M Univ., College Station.

Bandy, W.L., Hilde, T.W.C., 2000. Morphology and recent history of the ridge propagator system located at $18^{\circ} \mathrm{N}, 106^{\circ} \mathrm{W}$. In:

Delgado-Granados, H., Aguirre-Díaz, G., Stock, J.M. (Eds.) Cenozoic Tectonics and Volcanism of Mexico. Geological Society of America Special Paper 334, pp. 29-40.

Bandy, W.L., Kostoglodov, V., Mortera-Gutiérrez, C.A., 1998a. Southwest migration of the instantaneous Rivera-Pacific Euler pole since 0.78 Ma. Geofis. Int. 37, 153-169. 
Bandy, W.L., Kostoglodov, V.V., Mortera-Gutierrez, C.A., Urrutia-Fucugauchi, J., 1998b. Comment on "Relative motions of the Pacific, Rivera, North American, and Cocos plates since ).78 Ma" by Charles DeMets and Douglas S. Wilson. J. Geophys. Res. 103, 24,245-24,250.

Bandy, W.L., Hilde, T.W.C., Yan, C.-Y., 2000. The Rivera-Cocos plate boundary: Implications for Rivera-Cocos relative motion and plate fragmentation. In: Delgado-Granados, H., Aguirre-Díaz, G., Stock, J.M. (Eds.) Cenozoic Tectonics and Volcanism of Mexico. Geological Society of America Special Paper 334, pp. 1-28.

Bandy, W.L., Michaud, F., Bourgois, J., Calmus, T., Dyment, J., Mortera-Gutiérrez, C.A., Ortega-Ramírez, J., Pontoise, B., Royer, J.Y., Sichler, B., Sosson, M., Rebolledo-Vieyra, Bigot-Cormier, Díaz-Molina, O., Hurtado-Artunduaga, A.D., Pardo-Castro, G., Trouillard-Perrot, C., 2005. Subsidence and strike-slip tectonism of the upper continental slope off Manzanillo, Mexico.

Tectonophysics, 398, 115-140.

Bandy, W.L., Michaud, F., Dyment, J., Mortera Gutierrez, C., Bourgois, B., Calmus, T., Sosson, M., Ortega Ramirez, J. Royer, J.-C., Pontoise, B., Sichler B., 2007. New constraints on Rivera-Pacific relative motion from multibeam bathymetric data along the MSS and Rivera transform, 2007 Joint Assembly of the AGU, Acapulco, Mexico, Meeting Abstracts, S31A-12. 
Bevington, P.R., 1969. Data Reduction and Error Analysis for the Physical Sciences. McGraw-Hill, New York.

Bourgois, J., Renard, V., Aubouin, J., Bandy, W., Barrier, E., Calmus, T., Carfantan, J.-C., Guerrero, J., Mammerickx, J., Mercier de Lepinay, B., Michaud, F., Sosson, M., 1998. The East Pacific rise-Rivera Fracture Zone eastern junction off Mexico. C.R. Acad. Sci. Paris t.307, Serie II, 617-626.

Cande, S.C., Kent, D.V., 1995. Revised calibration of the geomagnetic polarity timescale for the Late Cretaceous and Cenozoic. J. Geophys. Res., 100, 6093-6095.

Crane, K., 1979. The Galapagos rift at $86^{\circ} \mathrm{W}$ : Morphological wave forms; evidence for a propagating rift. J. Geophys. Res. 84, 60116018.

DeMets, C., Stein, S., 1990. Present-day kinematics of the Rivera plate and implications for tectonics of southwestern Mexico. J. Geophys. Res. 95, 21,931-21,948. 
DeMets, C., Wilson, D.S., 1997. Relative motions of the Pacific, Rivera, North American, and Cocos plates since 0.78 Ma. J.

Geophys. Res. 102, 2789-2806.

DeMets, C., Traylen, S., 2000. Motion of the Rivera plate since 10 Ma relative to the Pacific and North American plates and the mantle. Tectonophys. 318, 119-159.

Freund, R., 1974. Kinematics of transform and transcurrent faults. Tectonophysics 21, 93-134.

Gordon, R.G., 1995. Plate motions, crustal and lithospheric mobility, and paleomagnetism: Prospective viewpoint. J. Geophys. Res. 100, 24,367-24,392.

Kleinrock, M.C., Hey, R.N., 1989a. Detailed tectonics near the tip of the Galapagos $95.5^{\circ} \mathrm{W}$ propagator: How the lithosphere tears and a spreading axis develops. J. Geophys. Res. 94, 13,801-13,838.

Kleinrock, M.C., Hey, R.N., 1989b. Migrating transform zone and lithospheric transfer at the Galapagos $95.5^{\circ} \mathrm{W}$ propagator. J. Geophys. Res. 13,859-13,878. 
Kostoglodov, V.V., Bandy, W., 1995. Seismotectonic constraints on the convergence rate between the Rivera and North American plates. J. Geophys. Res. 100, 17977-17989.

LePichon, X., 1968. Sea-floor spreading and continental drift. J. Geophys. Res. 73, 3661-3697.

Lonsdale, P., 1995. Segmentation and disruption of the East Pacific Rise in the mouth of the Gulf of California. Mar. Geophys. Res. $17,323-359$.

Macdonald, K.C., Castillo, D.A., Miller, S.P., Fox, P., Kastens, K.A., Bonatti, E., 1986. Deep-Tow studies of the Vema Fracture Zone 1. Tectonics of a major slow slipping transform fault and its intersection with the Mid-Atlantic ridge. J. Geophys. Res. 91, $3334-3354$.

Mammerickx, J., Carmichael, I.S.E., 1989. A spreading incursion in the continent near the Rivera plate and Jalisco block?. EOS,

Trans. Am. Geophys. Un. 70, 1318-1319.

Mammerickx, J., Sandwell, D., 1986. Rifting of Old Oceanic Lithosphere. J. Geophys. Res. 91, 1975-1988. 
Mammerickx, J., Naar, D.F., Tyce, R.L., 1988. The Mathematician Paleo-plate. J. Geophys. Res. 93, 3025-3040.

Merrill, R.T., McElhinny, M.W., 1983. The Earth's Magnetic Field: Its History, Origin and Planetary Perspective, International Geophysical Series vol. 32, Academic Press, New York.

Michaud, F., Royer, J.-Y., Bourgois, J., Mercier de Lepinay, B., 1996. Comment on "Segmentation and Disruption of the East Pacific rise in the Mouth of the Gulf of California" by Peter Lonsdale (Marine Geophysical Researches 17, pp. 323-359, 1995). Marine Geophysical Researches 18, 597-599.

Michaud, F., Royer, J.-Y., Bourgois, J., Mercier de Lepinay, B., Liaudon, G.P., 1997. The Rivera Fracture Zone revisited. Marine Geol. 137, 207-225.

Morgan, W.J., 1968. Rises, trenches, great faults, and crustal blocks. J. Geophys. Res. 73, 1959-1982. 
Pacheco, J., Singh, S.K., Dominguez, J., Hurtado, A., Quintanar, L., Jiménez, Z., Yamamoto, J., Gutiérrez, C., Santoyo, M., Bandy, W., Guzmán, M., Kostoglodov, V., 1997. The October 9, 1995 Colima-Jalisco, México earthquake (Mw 8): an aftershock study and a comparison of this earthquake with those of 1932. Geophys. Res. Lett. 24, 2223-2226.

Pockalny, R.A., Fox, P.J., Fornari, D.J., Macdonald, K.C., Perfit, M.R., 1997. Tectonic reconstruction of the Clipperton and Siqueiros fracture zones: Evidence and consequences of plate motion change for the last 3 Myr. J. Geophys. Res. 102, 3167-3181.

Rabinowitz, P.D., Purdy, G.M., 1976. The Kane frcture zone in the western central Atlantic Ocean. Earth Planet. Sci. Letts. 33 , $21-26$.

Schouten, H., McCamy, K., 1972. Filtering marine magnetic anomalies. J. Geophys. Res. 35, 7089-7099.

Singh, S.K., Lermo, J., 1985. Mislocation of Mexican earthquakes as reported in international bulletins. Geof. Int. 24, $333-351$.

Singh, S.K., Pacheco, J.F., Alcántara, L., Reyes, G., Ordaz, M., Inglesias, A., Alcocer, S.M., Gutierrez, C., Valdés, C., Kostoglodov, V., Reyes, C., Mikumo, T., Quass, R., Anderson, J.G., 2003. A preliminary report on the Tecomán, Mexico earthquake of 22 January 2003 (Mw 7.4) and its effects. Seismol. Res. Lett. 74, 279-289. 
Singh, S.K., Ponce, L., and Nishenko, S., 1985. The great Jalisco, Mexico, earthquake of 1932: Subduction of the Rivera plate. Bull. Seism. Soc. Am. 75, 1301-1313.

Wilson, D.S., DeMets, C., 1998. Reply. J. Geophys. Res. 103, 24,251-24,256.

Zobin, V.M., 1997. The rupture history of the Mw 8.0 Jalisco, Mexico, earthquake of 1995 October 9. Geophys. J. Intern. 130, 220228. 


\section{Figure Captions}

Fig. 1. Location of study area (Dashed-Box). Also shown are the locations of previously published Rivera-Pacific Euler poles of Bandy (1992) (filled star), Bandy et al. (1998a) (filled circle), Lonsdale (1995) (filled square), DeMets and Stein (1990) (filled triangle), DeMets and Wilson (1997) (filled diamond), DeMets and Traylen (2000) (X), and the new models, B2007-1 and B2007-2 which are constrained by the new data and results of this study. Note that the area marked by a question mark in the NW corner of the Rivera plate is most likely not acting as a rigid part of the plate (Lonsdale, 1995). Abbreviations are EPR = East Pacific Rise; MSS = Moctezuma Spreading Segment; MAT = Middle America Trench; RT = Rivera Transform. Basemap from Geo-Map Applications.

Fig. 2. Map of morphotectonic features and magnetic anomaly identifications (after Bandy, 1992; Bandy et al., 2000; Bandy and Hilde, 2000). The grey lines in the background are magnetic anomaly lineations plotted along ship tracks, the data was obtained from the NGDC, Boulder Colorado, USA. Abbreviations are: MAT = Middle America Trench; RFZ = Rivera Fracture Zone; Paleo-RT = Paleo-Rivera Transform; EPR = East Pacific Rise; OTPF = Outer Tectonic Pseudofault; ORSB = Outer Rough-Smooth boundary; MSS = Moctezuma Spreading Segment; IRSB = Inner Rough-Smooth Boundary; ITPF = Inner Tectonic Pseudofault; RRS = Relict Ridge Segment. 
Fig. 3. Location map of ship tracks of the BART and FAMEX projects (solid black lines) and those data obtained from the NGDC (dashed black lines). Numbers on ship tracks are the profile numbers used herein. MSS = Moctezuma Spreading Segment; RT = Rivera Transform.

Fig. 4. Bathymetry map constructed from the new multibeam data. C.I. $=100$ meters. Abbreviations are: MSS $=$ Motezuma Spreading Segment; RFZ = Rivera Fracture Zone; PRT = Paleo-Rivera Transform; RT = Rivera Transform.

Fig. 5. Top: Uninterpreted sidescan mosaic, map view. Dark and light shades mark areas of high and low backscatter strengths, respectively. Bottom: Same sidescan mosaic draped on the new multibeam bathymetry. PTDZ = Principle Transform Displacement Zone.

Fig. 6. Sidescan mosaic illustrating the major morphotectonic zones (A-G) and morphotectonic elements. Dark and light shades mark areas of high and low backscatter strengths, respectively. The outer and inner tectonic psuedofaults (Bold solid lines) are designated as OTPF and ITPF, respectively. The outer and inner rough-smooth boundaries (Bold dash-double dot lines) are deginated as ORSB and IRSB, respectively. The transform tectonized zone lies between the dash-dot lines. RFZ= Rivera Fracture Zone; PRT = PaleoRivera Transform; RT=Rivera Transform. See text for a discussion of the morphologic zones. 
Fig. 7. Top: 3-D image of seafloor reflectivity mosaic draped on the multibeam bathymetry near the intersection (white dot) of the Rivera transform and the MSS. View is towards the north. Note that the Rivera transform climbs up the northern transform wall as it approached the intersection. Bottom: Same data, now looking towards the east, better illustrating the location of the PTDZ of the Rivera transform as it approaches its intersection with the MSS.

Fig. 8. 3-D image of seafloor reflectivity mosaic draped on the multibeam bathymetry illustrating the nature of morphologic zones $\mathrm{C}$ and $\mathrm{D}$ and the West-Ridge.

Fig. 9. Top: Sidescan mosaic illustrating the location and orientations of the Rivera Fracture Zone (RFZ) and Paleo-Rivera Transform (Paleo-RT). The numbers 91 and 95 located at the eastern end of the Rivera Fracture zone are the azimuths of the strike of the top and base of the escarpment, respectively. Also indicated are the two possible locations of the inner tectonic pseudofaults (ITPF). MSS $=$ Moctezuma Spreading Center. Bottom: Same sidescan mosaic draped on the multibeam bathymetry. 
Fig. 10. Top: sidescan mosaic drapped on the multibeam bathymetry illustrating the orientations of the PTDZ of the Rivera Transform along transform segments $\mathrm{C}$ through $\mathrm{G}$. Also shown are the focal mechanism solutions (Harvard CMT catalogue) and slip vector azimuths in degrees clockwise from north (in parentheses). Bottom: Bathymetric map of same area.

Fig. 11. Top: sidescan mosaic in the area of transform segments A and B adjacent to the intersection of the MSS and the Rivera transform. Numbers above segment label are the azimuths of the segments in degrees clockwise from geographic north. Bottom: Bathymetric map of the same area. Solid line marks trend of Rivera Transform picked by Bourgois et al. (1988). Dashed line marks location of lineament observed on the above sidescan image.

Fig. 12. Magnetic anomalies plotted along ship tracks. Positive anomalies are shaded. Anomaly designations from Cande and Kent (1995).

Fig. 13. Comparison of two possible models (A: Model-1, B: model-2) and magnetic anomalies observed along profile P3 (modeled and observed anomalies are marked by dashed and solid lines, respectively). Shown in the center is the bathymetric profile along profile P3. Spreading rates (in $\mathrm{cm} / \mathrm{yr}$ ) shown are the half rates used to generate the models. See figure 12 for location of profile P3. 
Fig. 14. Magnetic anomaly values plotted along profile P3 (upper curve). Identifications are estimated by assuming that seafloor spreading has occurred both at the MSS and at the west-ridge since $0.9 \mathrm{Ma}$. If correct, the combined spreading rate is $\sim 7.2 \mathrm{~cm} / \mathrm{yr}$. Also shown is the bathymetric profile along profile $\mathrm{P} 3$.

Fig. 15. Cartoon illustrating the expected geometry of transform due to (1) a change in plate motion (top panel), (2) no plate motion change and no block rotation (lower panel, left side) and (3) no plate motion change with block rotation (lower panel, right side).

Fig. 16. Plot illustrating the fit between the azimuths of the Rivera Transform predicted from the best-fit pole of the various models and the azimuths observed on the new bathymetric and sidescan images at the centers of the Rivera transform segments A, B, C, D, F and G, and at the eastern end of the Rivera Fracture Zone. The residual is defined as the predicted azimuth minus the observed azimuth. The vertical bars indicate the uncertainties associated with the observed azimuths. 


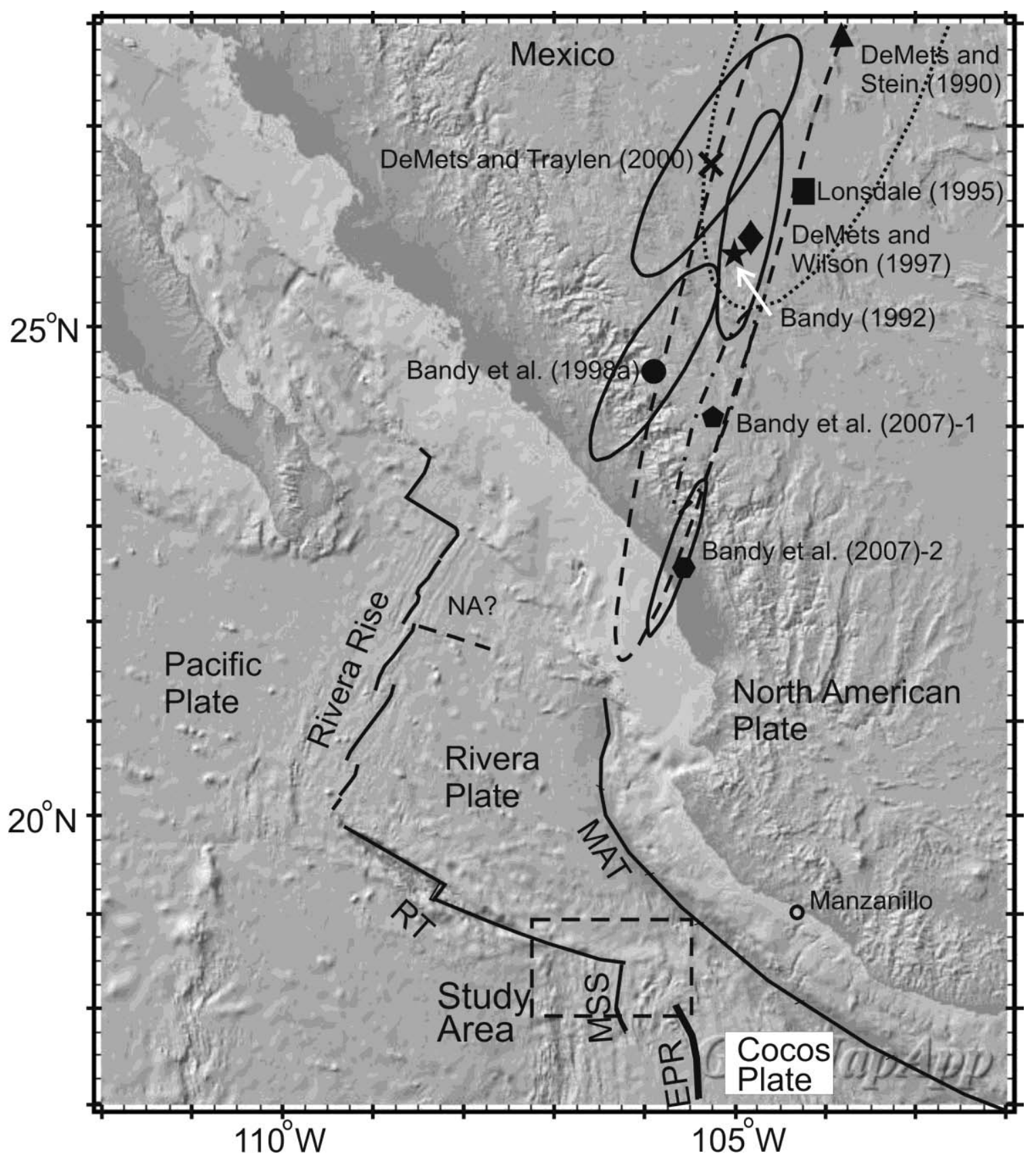


Figure 1

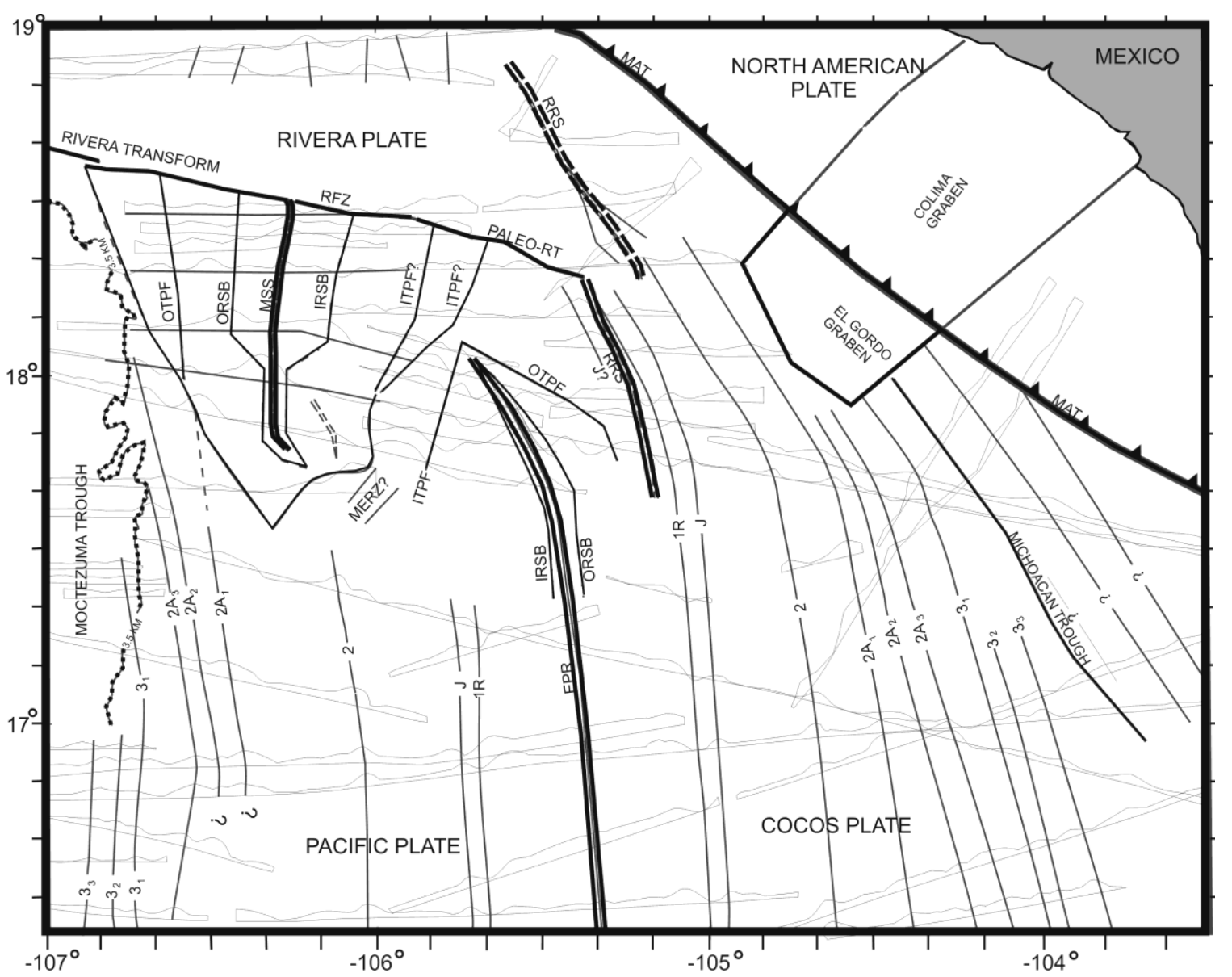

Figure 2. 


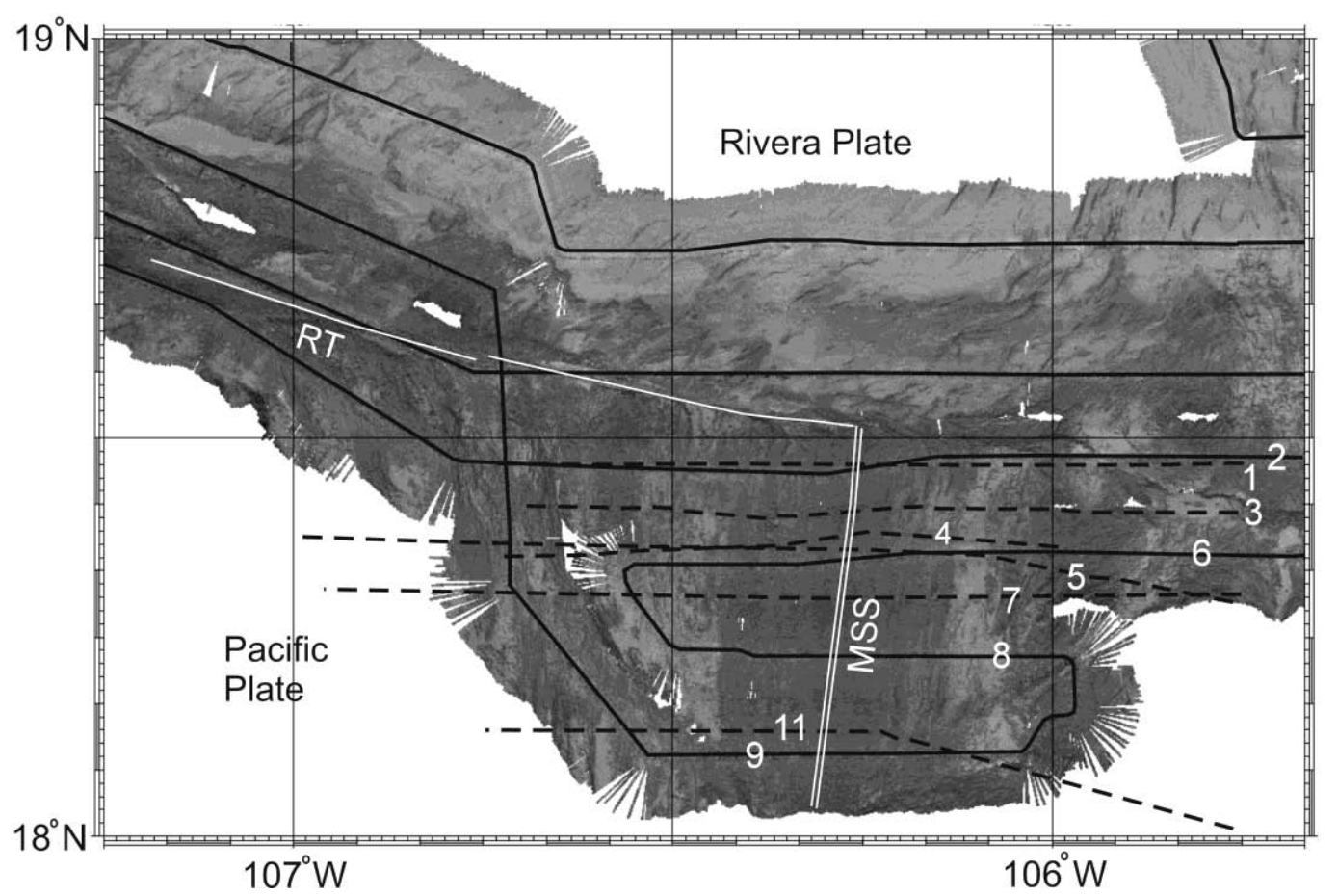

Figure 3 


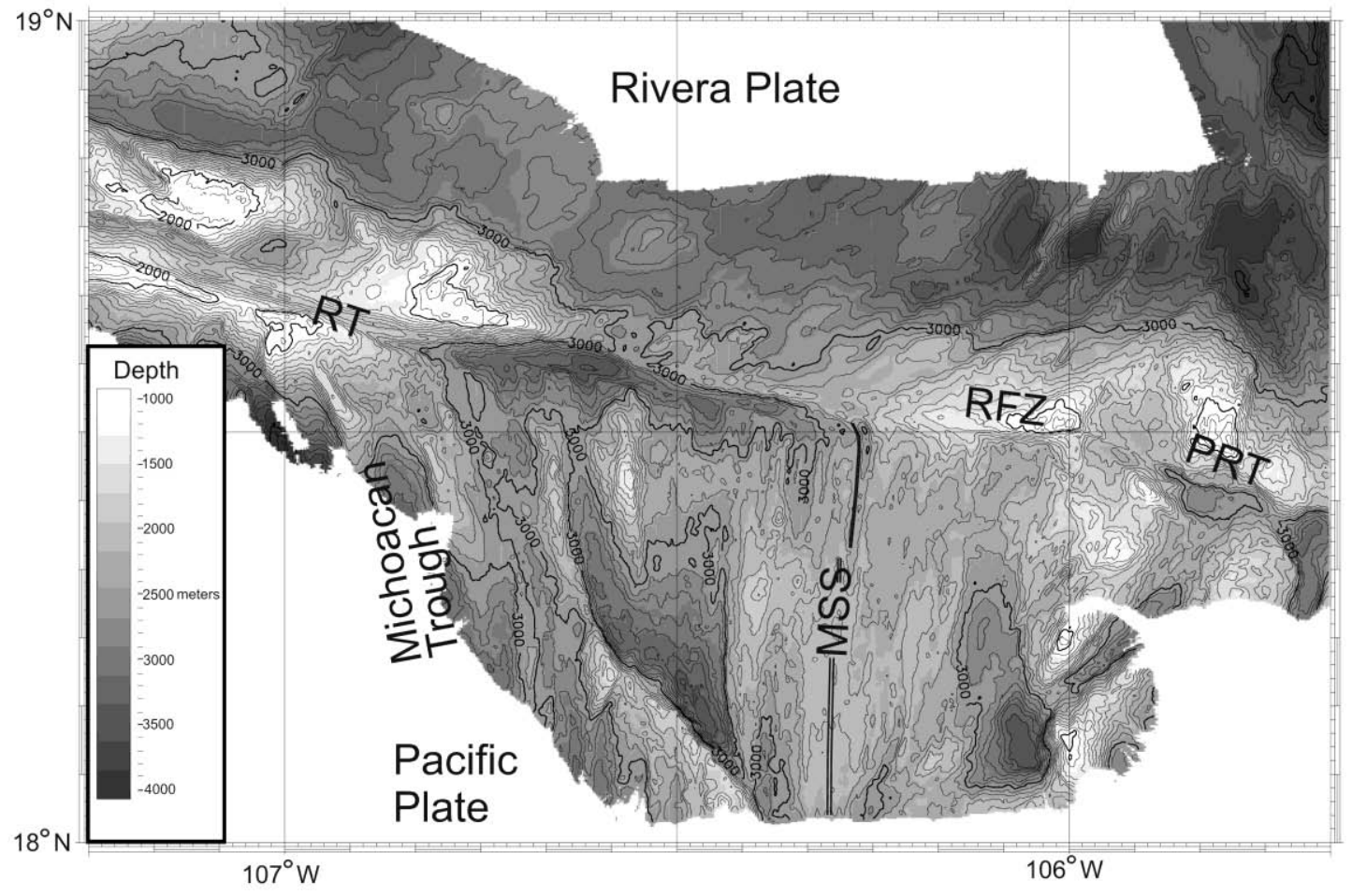

Figure 4. 

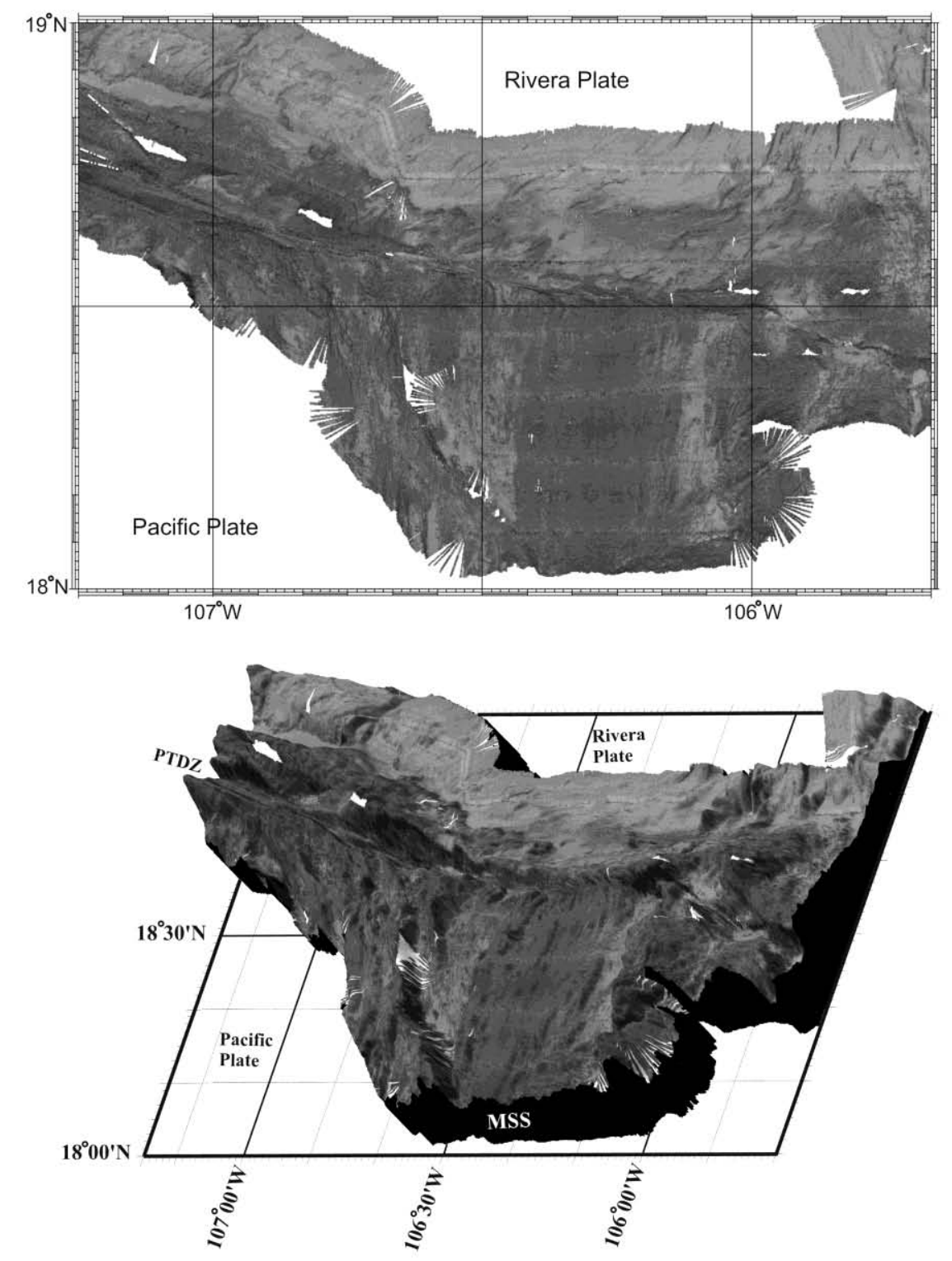
Figure 5.

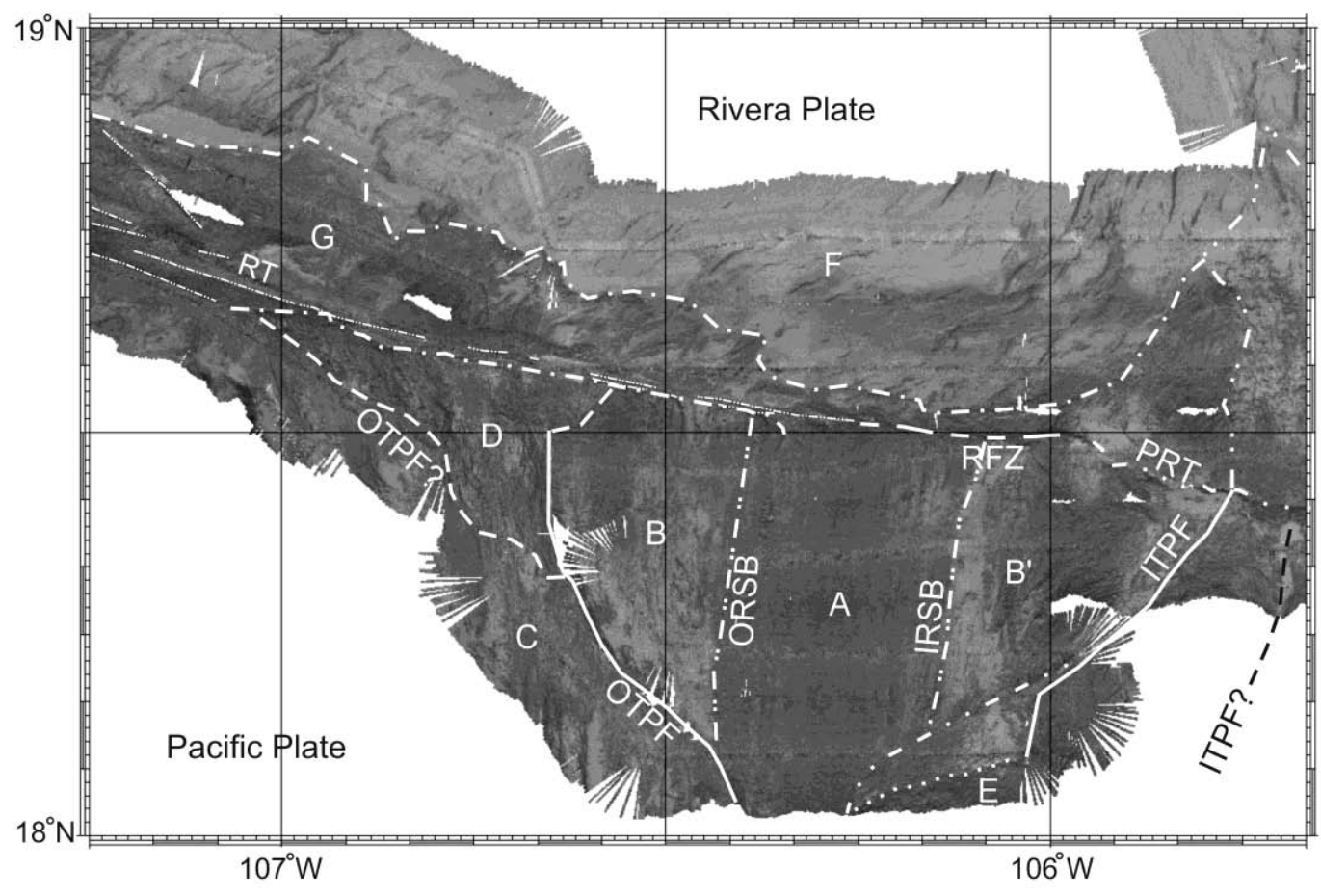

Figure 6. 

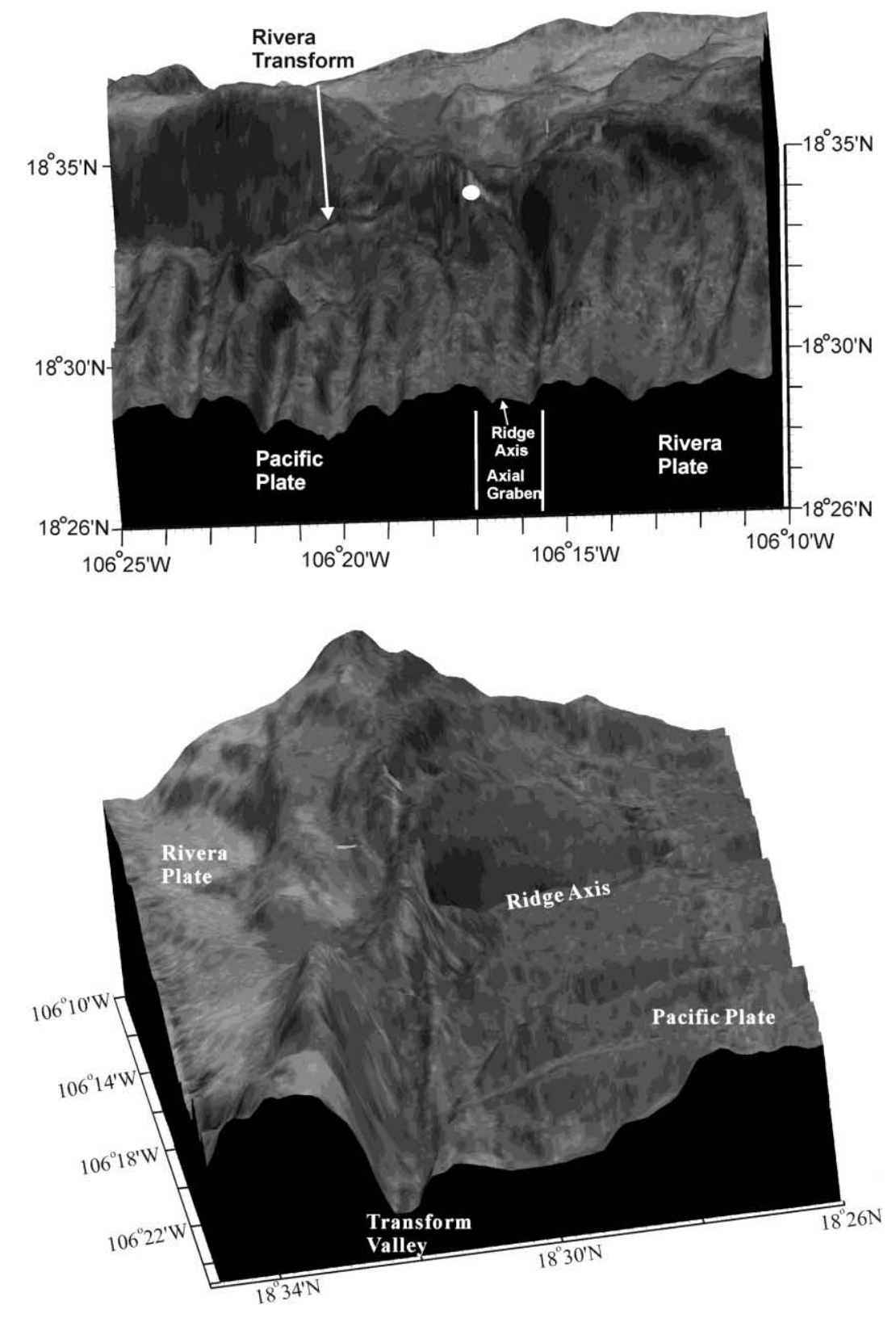
Figure 7.

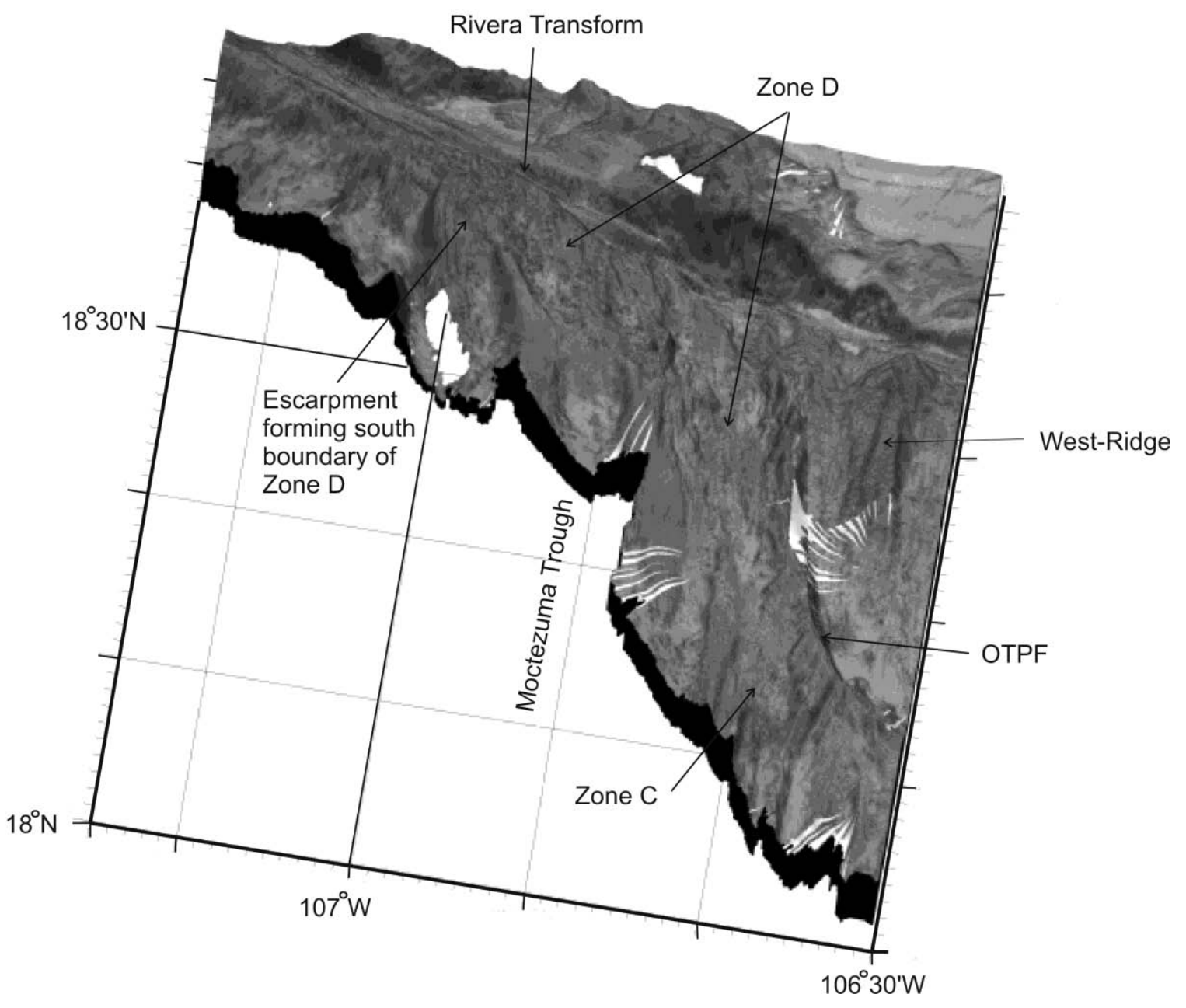


Figure 8. 


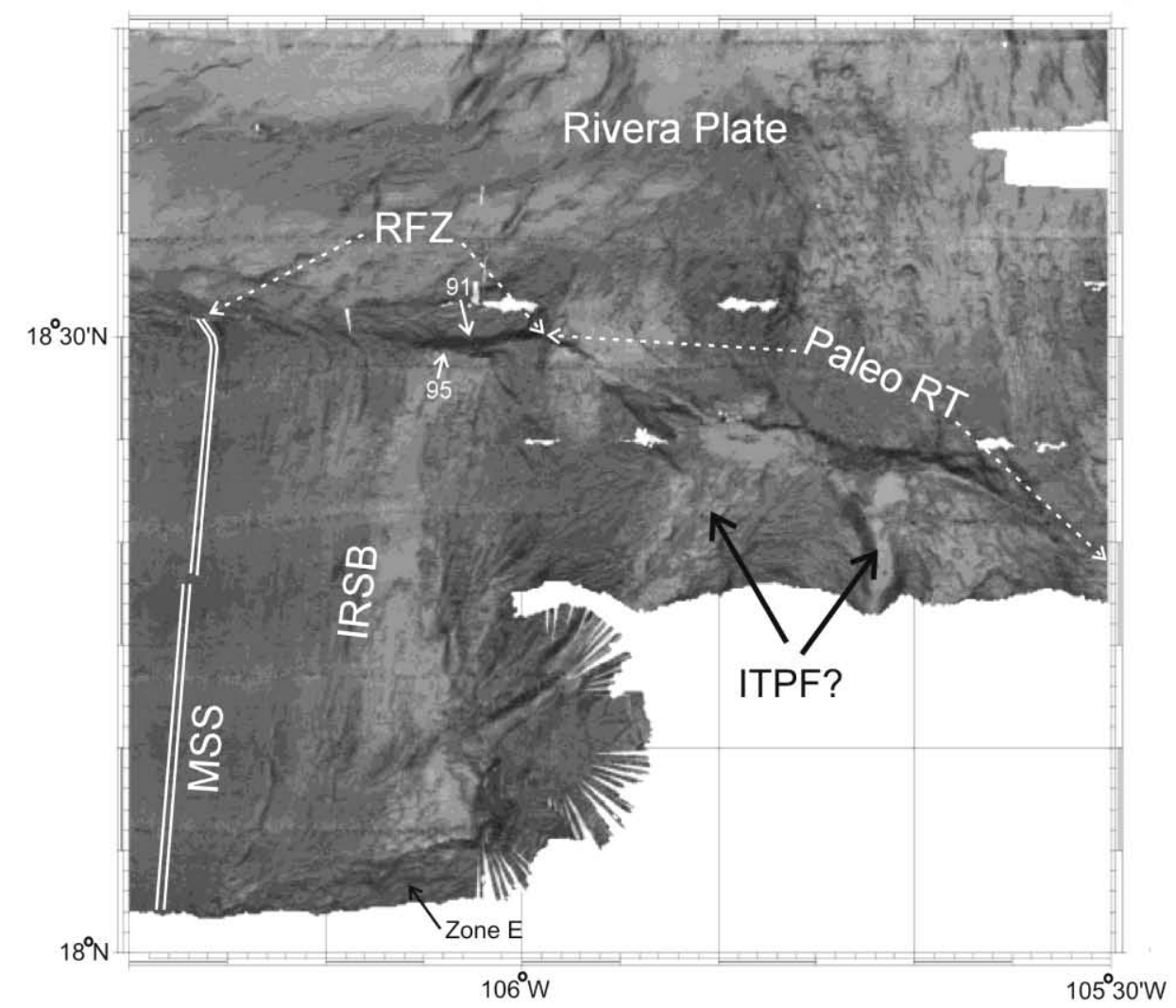

Rivera Fracture Zone

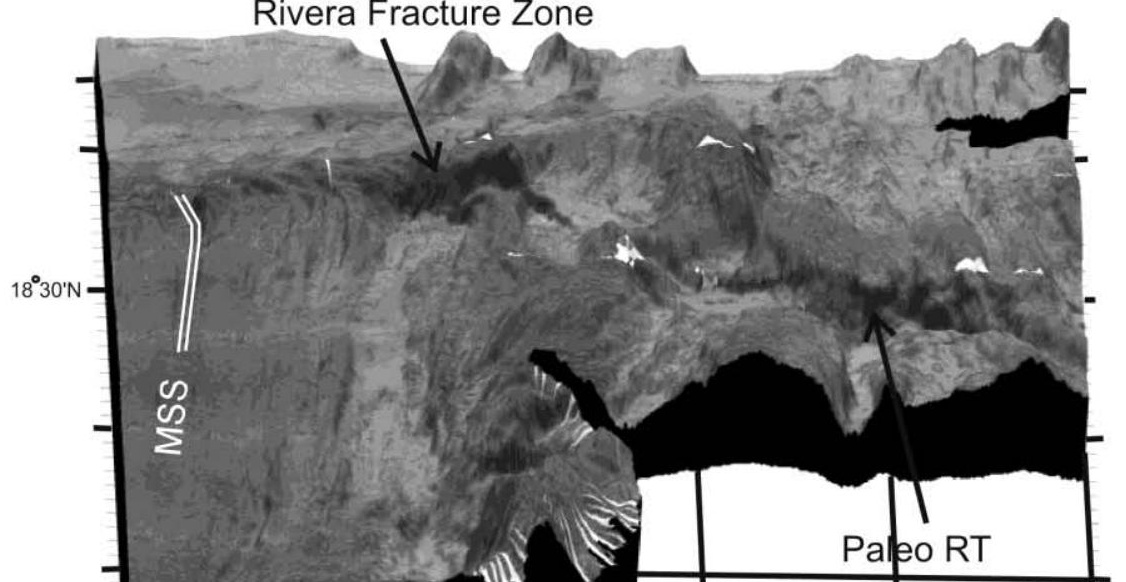


Figure 9. 

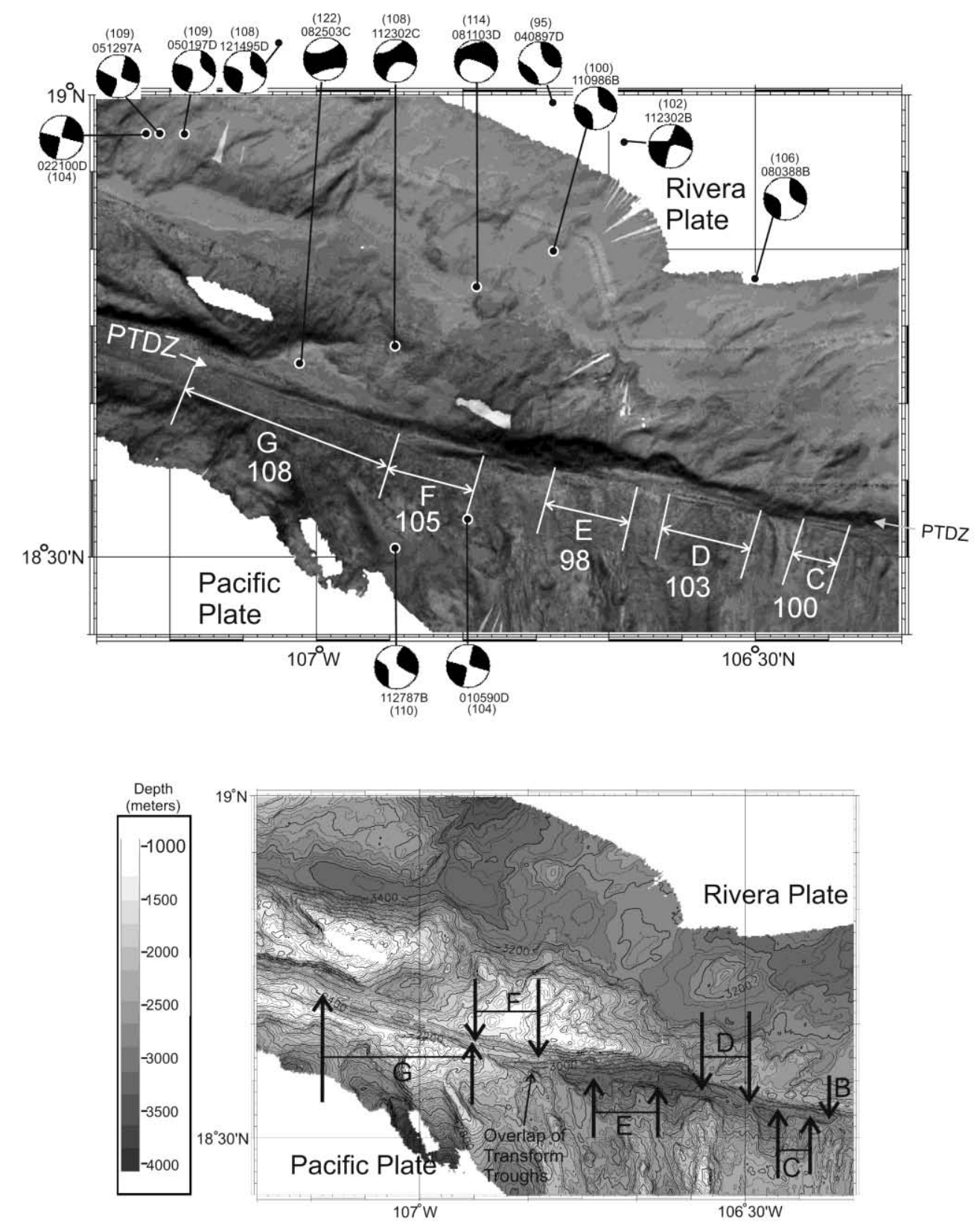
Figure 10. 

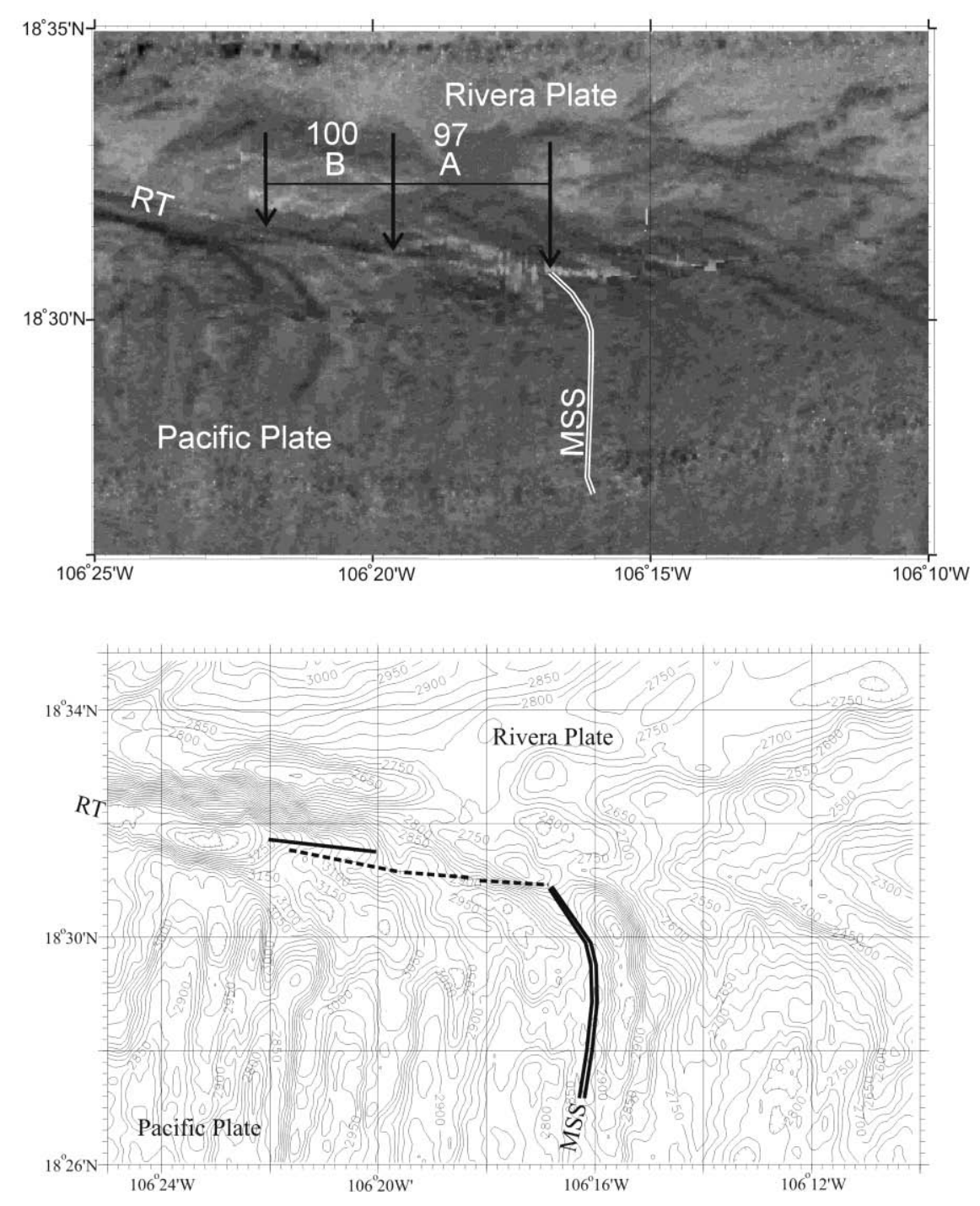
Figure 11.

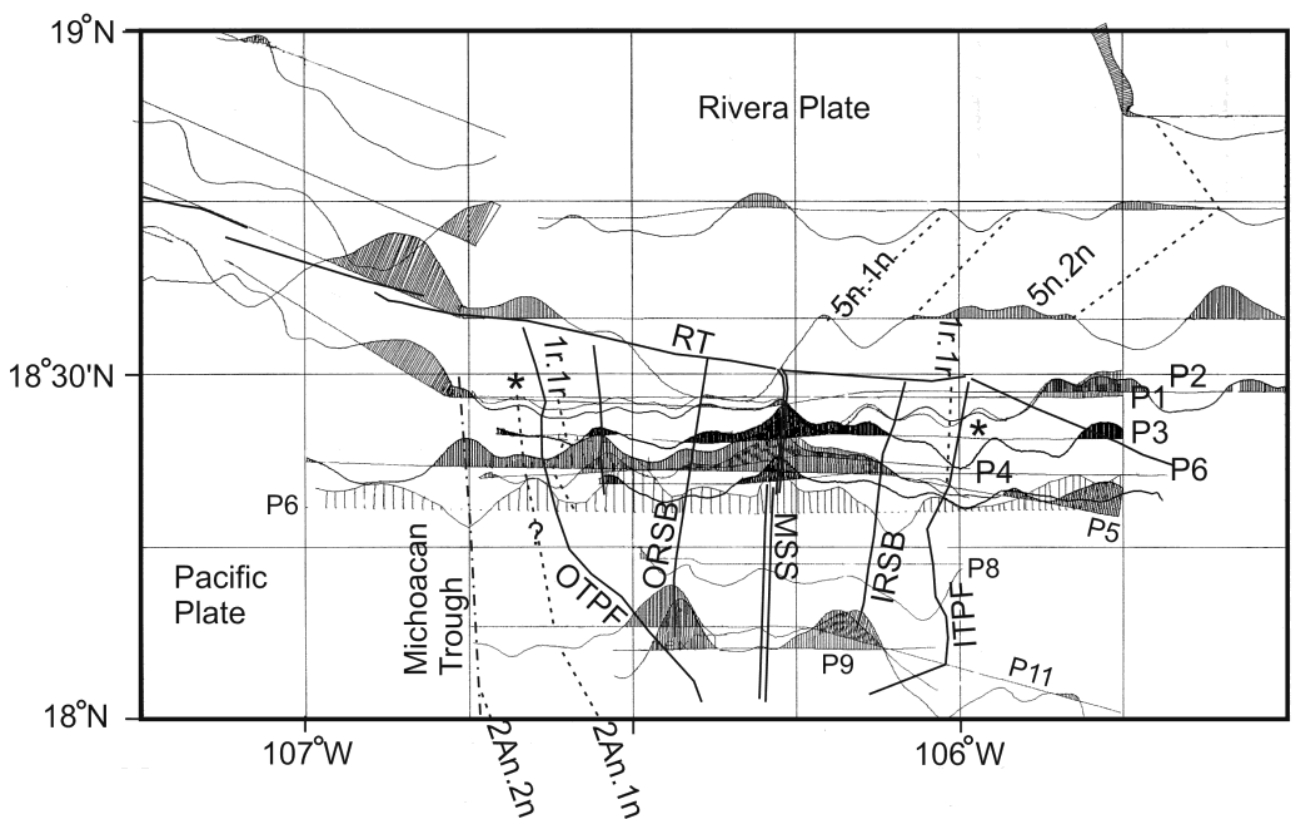

Figure 12. 

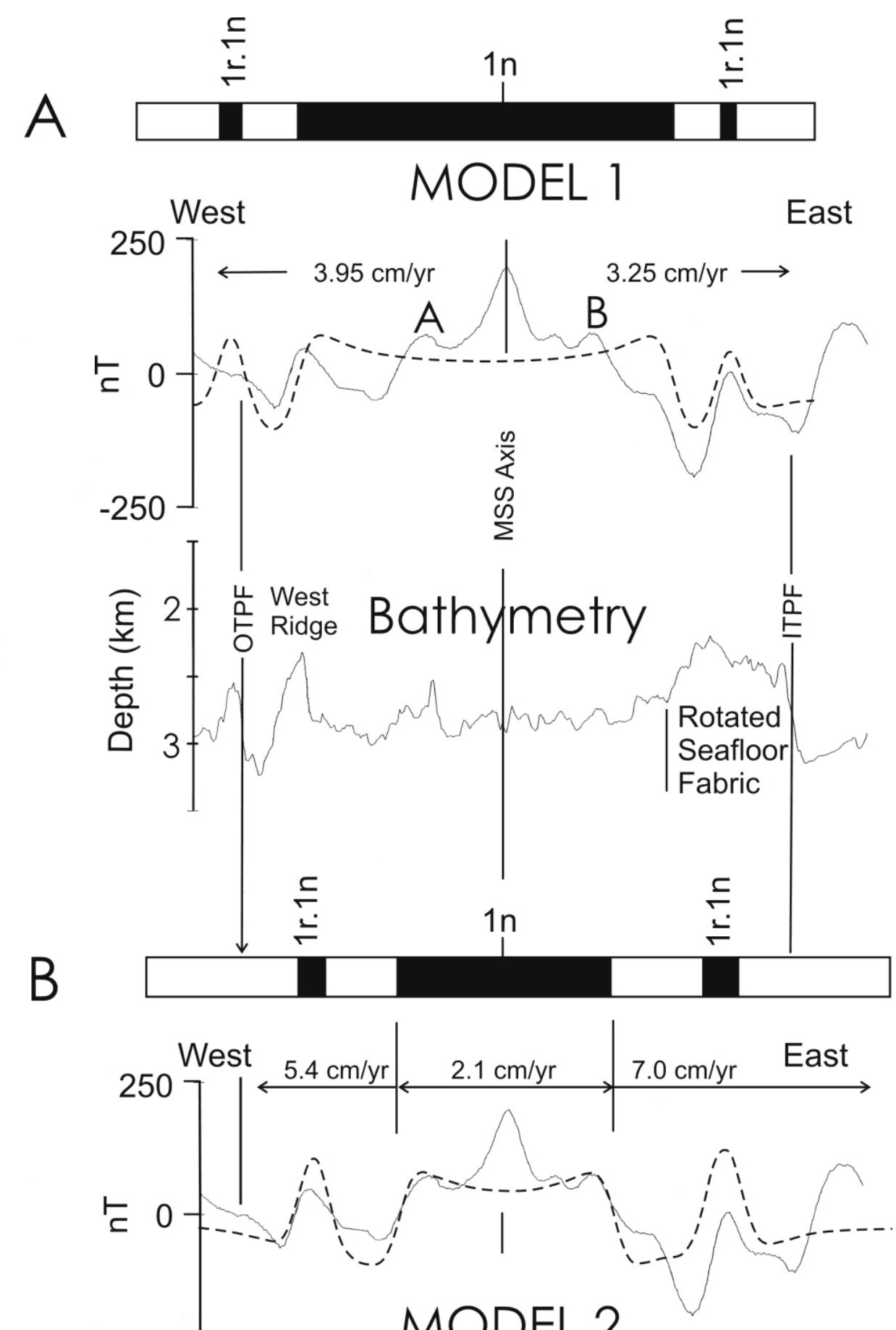
Figure 13. 


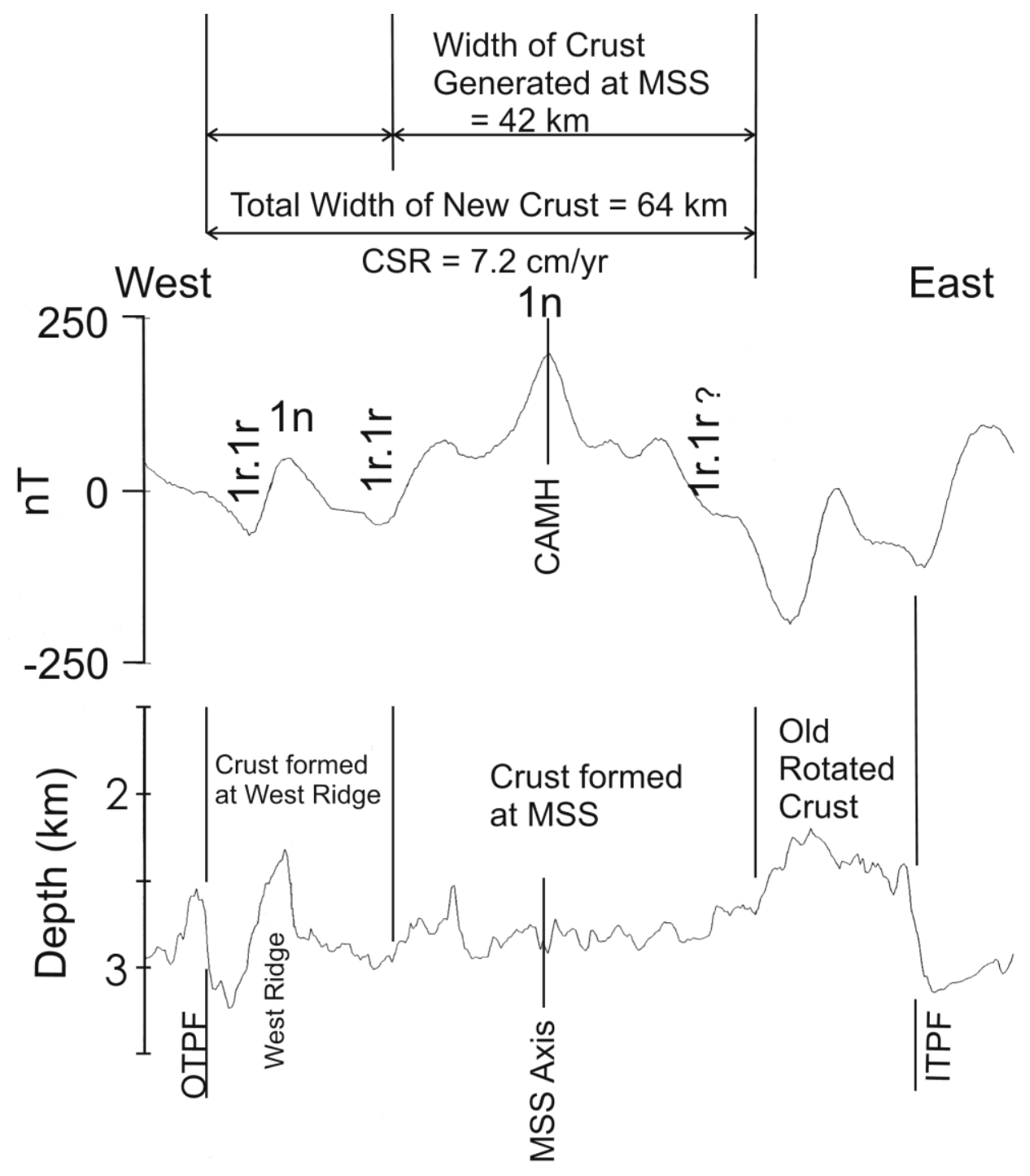


Figure 14.

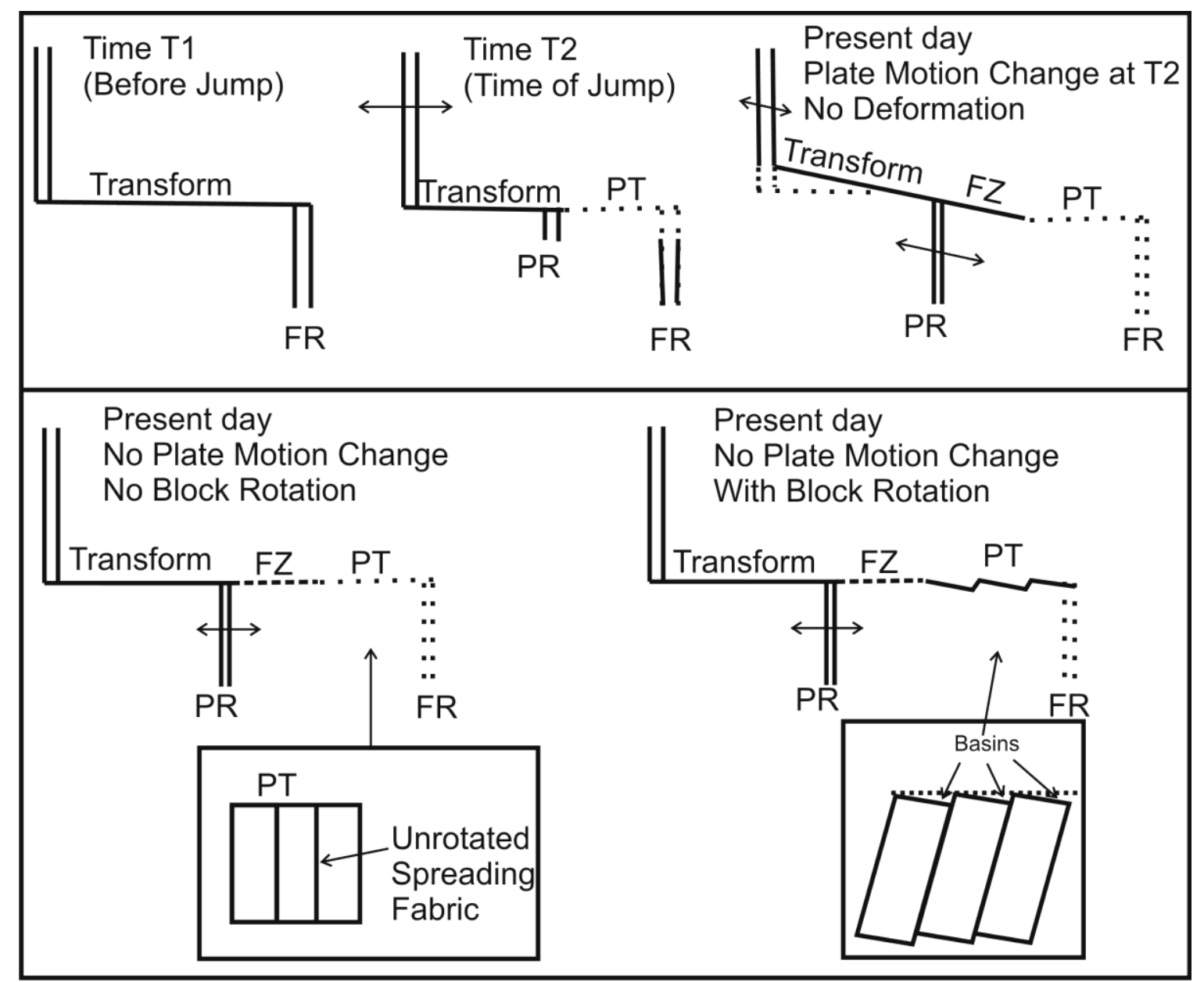

Figure 15. 
PREDICTED-OBSERVED AZIMUTHS

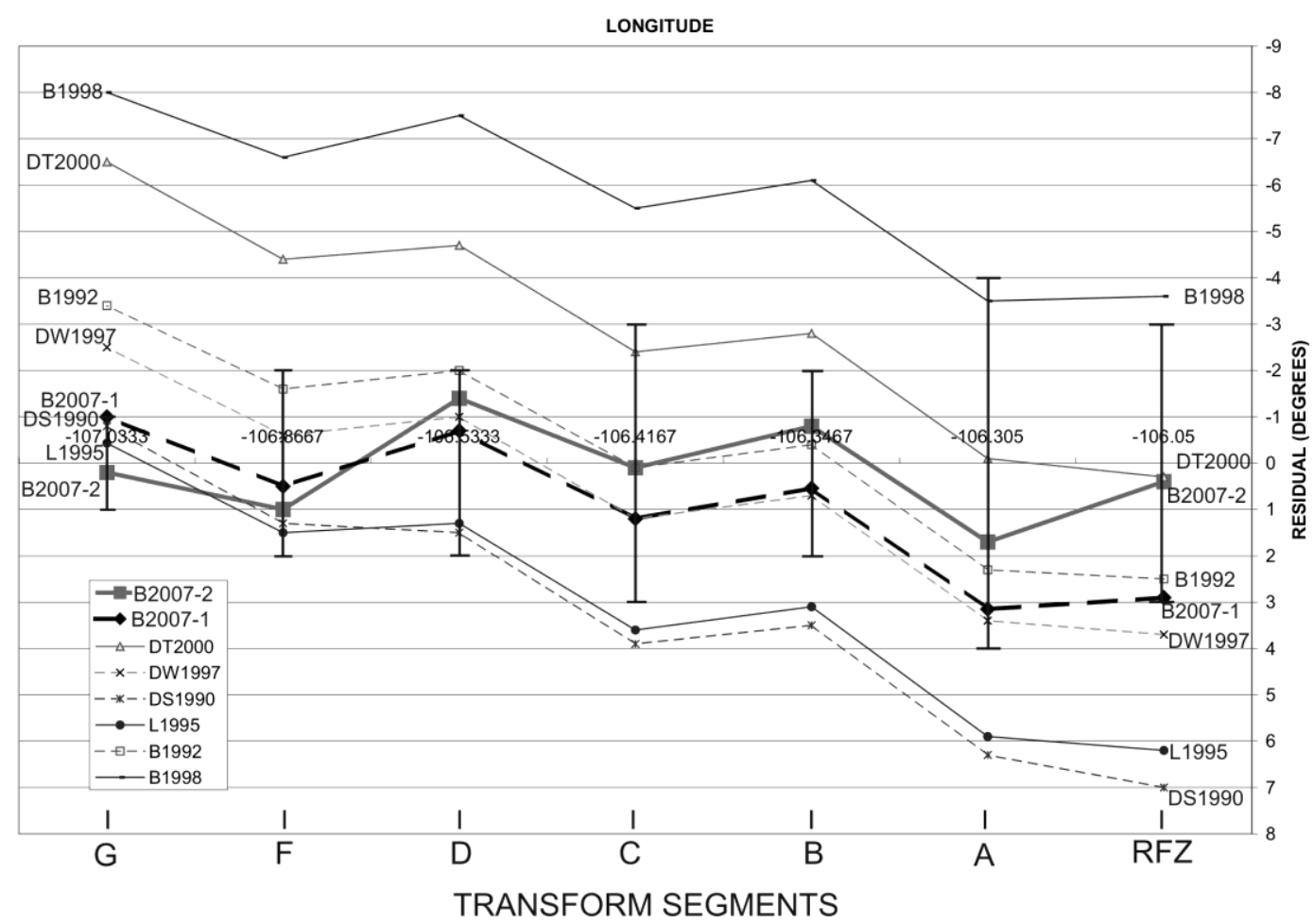

Figure 16. 


\begin{tabular}{|c|c|c|c|c|c|c|c|}
\hline Model & $\begin{array}{l}\text { Latitude } \\
\left({ }^{\circ} \mathrm{N}\right)\end{array}$ & $\begin{array}{l}\text { Longitude } \\
\text { ("W) }\end{array}$ & $\begin{array}{c}(1) \\
(\% / m . y .)\end{array}$ & $\begin{array}{c}\text { Predicted } \\
\text { Azimuth }{ }^{\text {"n }} \text { of } \\
\text { eastern Rivera } \\
\text { Transform }\end{array}$ & $\begin{array}{l}\text { MSS rate } \\
\text { data used? }\end{array}$ & $\begin{array}{c}\text { Rivera Rise } \\
\text { rate/magnetic } \\
\text { data used in } \\
\text { pole } \\
\text { determination? }\end{array}$ & $\begin{array}{l}\text { Orthogonal } \\
\text { spreading along } \\
\text { Rivera-Rise } \\
\text { used to } \\
\text { constrain pole }\end{array}$ \\
\hline $\begin{array}{l}\text { DeMets and } \\
\text { Stein (1990) }\end{array}$ & 27.9 & 103.8 & 3.986 & 103 & No & Yes & Yes \\
\hline Bandy (1992) & 25.7 & 105.0 & ........ & 99 & No & No & No \\
\hline $\begin{array}{l}\text { Lonsdale } \\
\text { (1995) }\end{array}$ & 26.4 & 104.3 & 4.65 & 103 & No & $\mathrm{No}^{* * *}$ & Yes \\
\hline $\begin{array}{l}\text { DeMets and } \\
\text { Wilson (1997) }\end{array}$ & 25.9 & 104.8 & 4.971 & 100 & Yes & Yes & ? \\
\hline $\begin{array}{l}\text { Bandy et al. } \\
\text { (1998) }\end{array}$ & 24.62 & 105.89 & 6.45 & 94 & No & $\mathrm{No}^{*+*}$ & Yes \\
\hline $\begin{array}{l}\text { DeMets and } \\
\text { Traylen } \\
(2000)\end{array}$ & 26.7 & 105.2 & 4.69 & 97 & No & Yes & Yes \\
\hline B2007-2* & 22.61 & 105.63 & 8.30 & 99 & No & $\mathrm{No}^{\mathrm{rmx}}$ & \\
\hline B2007-1 ${ }^{*}$ & 24.10 & 105.21 & 6.35 & 100 & No & $\mathrm{No}^{* * *}$ & No \\
\hline
\end{tabular}

Sole difference between these models is the trend of the Rivera Transform at its intersection with the Rivera Rise.

"... All azimuths are in degrees as measured clockwise from geographic north.

In these models only one rate measurement was used, or the pole was fixed when determining the angular rotation rates. 